\title{
Northern Hemisphere Winter Air Temperature Patterns and Their Associated Atmospheric and Ocean Conditions
}

\author{
JIECHUN DENG \\ Key Laboratory of Meteorological Disaster, Ministry of Education/Joint International Research Laboratory of Climate and \\ Environmental Change/Collaborative Innovation Center on Forecast and Evaluation of Meteorological Disasters, Nanjing \\ University of Information Science and Technology, Nanjing, China, and Department of Atmospheric and Environmental \\ Sciences, University at Albany, State University of New York, Albany, New York \\ Aiguo DAI \\ Department of Atmospheric and Environmental Sciences, University at Albany, State University of New York, Albany, \\ New York \\ DORINA CHYI \\ Key Laboratory of Meteorological Disaster, Ministry of Education/Joint International Research Laboratory of Climate and \\ Environmental Change/Collaborative Innovation Center on Forecast and Evaluation of Meteorological Disasters, Nanjing \\ University of Information Science and Technology, Nanjing, China
}

(Manuscript received 15 July 2019, in final form 17 April 2020)

\begin{abstract}
The Northern Hemisphere (NH) has experienced winter Arctic warming and continental cooling in recent decades, but the dominant patterns in winter surface air temperature (SAT) are not well understood. Here, a self-organizing map (SOM) analysis is performed to identify the leading patterns in winter daily SAT fields from 1979 to 2018, and their associated atmospheric and ocean conditions are also examined. Three distinct winter SAT patterns with two phases of nearly opposite signs and a time scale of 7-12 days are found: one pattern exhibits concurrent SAT anomalies of the same sign over North America (NA) and northern Eurasia, while the other two patterns show SAT anomalies of opposite signs between, respectively, NA and the Bering Sea, and the Kara Sea and East Asia (EA). Winter SAT variations may arise from changes in the SOM frequencies. Specifically, the observed increasing trends of winter cold extremes over NA, central Eurasia, and EA during 1998-2013 can be understood as a result of the increasing occurrences of some specific SAT patterns. These SOMs are closely related to poleward advection of midlatitude warm air and equatorward movements of polar cold airmass. These meridional displacements of cold and warm airmasses cause concurrent anomalies over different regions not only in SAT but also in water vapor and surface downward longwave radiation. Anomalous sea surface temperatures in the tropical Pacific, midlatitude North Pacific, and North Atlantic and anomalous Arctic sea ice concentrations also concur to support and maintain the anomalous atmospheric circulation that causes the SAT anomalies.
\end{abstract}

\section{Introduction}

Winter surface air temperature (SAT) in the extratropical Northern Hemisphere (NH) has exhibited significant cooling over both central Eurasia and North America since the early 1990s (Cohen et al. 2014; Luo et al. 2016), which is linked to the recent Arctic warming and sea ice loss (e.g., Kug et al. 2015; Yao et al. 2017; Luo

\footnotetext{
Corresponding author: Jiechun Deng, jcdeng@nuist.edu.cn
}

et al. 2018, 2019), although modeling studies suggest a weak influence on the midlatitudes from the Arctic (Chen et al. 2016; McCusker et al. 2016; Sun et al. 2016; Dai and Song 2020). Associated with this cooling, Northern Hemisphere midlatitudes have experienced cold, harsh winters in the recent decades (Westby et al. 2013; Cohen et al. 2014). For example, North America suffered extreme cold winters of 2013/14 (Baxter and Nigam 2015; Yu and Zhang 2015; Seager and Henderson 2016) and 2014/15 (Xie and Zhang 2017), Europe was 
extremely cold during the 2009/10 (Cattiaux et al. 2010) and 2013/14 (Masselink et al. 2016) winters, and East Asia experienced extreme cold outbreaks during the 2011/12 winter (Wu et al. 2017) and in January 2016 (Qian et al. 2018; Ma and Zhu 2019). To better understand these extreme events over different midlatitude regions, one needs to know whether there exist any prevailing patterns in Northern Hemisphere SAT anomaly fields and whether the occurrence frequencies of these spatial patterns have changed during the recent decades.

Distinct winter SAT anomaly patterns over North America and Eurasia have been investigated separately in the literature (e.g., Chen et al. 2014; T. W. Park et al. 2015; Wang et al. 2015; Singh et al. 2016; Abdillah et al. 2017). For example, Lin (2015) identified the dominant modes of subseasonal variability of North American winter SAT, including a pattern showing the same sign of SAT anomalies over the whole North American continent, and a pattern showing a dipole structure of opposite SAT anomalies between the northwest and southeast North American continent. Meanwhile, the warm-west/cool-east (WWCE) dipole pattern of winter SAT over North America, which is characterized by warm temperatures in western North America and cold anomalies in eastern North America, is found to occur more frequently during 1980-2015 (Singh et al. 2016). Over Eurasia, spatial patterns of anomalous temperatures differ among different composites of the northern and southern modes of the East Asian winter monsoon (Chen et al. 2014).

The leading patterns of winter SAT anomalies over the whole extratropical NH are, however, still not well understood. In particular, it is unclear whether the winter SAT anomaly patterns over North America, Eurasia, and the Arctic are linked, for example, through poleward movements of the warm airmass from the lower latitudes at one longitudinal section while equatorward movements of the polar airmass occur simultaneously at another longitudinal section. Using an empirical orthogonal function (EOF) analysis, Lin (2018) found two dominant subseasonal patterns of the winter SAT over the extratropical $\mathrm{NH}$, which are separately located in North America and Eurasia. Further, using a self-organizing map (SOM) approach, Chen et al. (2017) revealed the concurrent winter temperature anomalies over eastern Asia and eastern North America, which are closely associated with the anomalous temperatures over the Kara Sea and the Bering Strait, respectively. However, only the regional-mean SAT anomalies averaged over eastern Asia and eastern North America were subjected to the SOM analysis in their study, which excluded the Arctic region. Since winter extreme cold events over the $\mathrm{NH}$ midlatitudes often result from southward intrusions of cold polar airmasses (Francis and Vavrus 2012; Cohen et al. 2014; Kanno et al. 2015; Overland et al. 2015; Sun et al. 2016; $\mathrm{Wu}$ 2017), it is important to include the Arctic region in examining the SAT teleconnection patterns over the extratropical NH.

Anomalous large-scale atmospheric circulations are believed to cause winter temperature anomalies over the midlatitude continents. They include variations in the Arctic Oscillation (Park et al. 2011; Song and Wu 2018) and the Ural blocking (Luo et al. 2016; Yao et al. 2017) for East Asian cold surges, and the Pacific-North America (PNA) teleconnection pattern ( $\mathrm{Yu}$ and $\mathrm{Lin}$ 2019) and the North Pacific Oscillation (Linkin and Nigam 2008; Baxter and Nigam 2015) for North American winter SAT anomalies. However, large-scale anomalous circulations associated with SAT anomaly patterns over the entire extratropical $\mathrm{NH}$ are not sufficiently investigated, although a few studies attempted to address this issue. For example, Thompson et al. (2002) linked the weakening of the stratospheric polar vortex during 1958-99 to the concurrent colder temperature anomalies over the $\mathrm{NH}$ midlatitudes, including North America, northern Europe, and East Asia. Kanno et al. (2015) suggested that the East Asian and North American cold winters result from cold air outbreaks by the discharge of polar cold airmasses. However, these studies fail to explore the large-scale circulation anomalies associated with daily SAT anomaly patterns over the entire extratropical NH.

Winter ocean conditions also play a crucial role in driving anomalous winter temperatures over the $\mathrm{NH}$ midlatitudes, including sea surface temperatures (SSTs) (e.g., Wang and Fu 2000; Seager and Henderson 2016; Yu and Lin 2019) and Arctic sea ice concentration (SIC) (e.g., Wu et al. 2017; Chen and Luo 2017; Yao et al. 2018). For anomalous SST forcing, Chen et al. (2004) found that the East Asian cold surge occurs more (less) frequently during warm (cold) El Niño-Southern Oscillation (ENSO) winters, while Xie et al. (2017) suggested that different configurations of the ENSO and the Pacific decadal oscillation (PDO) exerted influences on the occurrences of different types of the extreme cold waves over the conterminous United States. For the Arctic SIC anomalies, recent rapid Arctic warming associated with the reduced SIC (Dai et al. 2019) is linked to increased frequencies of extreme cold events over Eurasia and North America (Wu et al. 2013; Chen and Luo 2017; Wu 2017), while other studies (e.g., Chen et al. 2016; McCusker et al. 2016; Sun et al. 2016; Dai and Song 2020) found no link between recent Arctic sea ice loss and Eurasian winter cooling. Since most previous studies mainly focused on oceanic roles in affecting SAT 
anomalies over a selected region, it is necessary to examine the anomalous ocean conditions associated with concurrent winter SAT anomalies over the midhigh latitudes of the entire $\mathrm{NH}$.

This study aims to address the following questions by applying the SOM clustering approach to winter daily SAT anomaly fields: 1) Are there any preferred anomaly patterns of winter daily SAT over the extratropical NH? If so, what are their spatial and temporal characteristics? 2) What are their associated atmospheric and ocean conditions? 3) Is there a linkage between changes in the occurrence frequencies of different SAT patterns and the recent changes in winter SAT (including cold and warm extremes) over midlatitude continents? This study differs from previous studies (e.g., Kug et al. 2015; Xie et al. 2017; Chen et al. 2017; Lin 2018) in that the leading patterns of winter daily SAT anomalies over the whole extratropical $\mathrm{NH}$ are identified using the SOM clustering method with a focus on teleconnection patterns caused by air-mass advection required by mass continuity, and their temporal relationships with interannual and interdecadal variability of winter-mean SAT anomalies and extreme events are also examined. Thus, our results improve current understanding on how changes in daily weather patterns affect seasonal mean SAT variations and long-term changes.

The remainder of the paper is organized as follows. In section 2, we describe the methodology, including the reanalysis data and the SOM approach. Section 3 explains the implications of the SAT teleconnection patterns, with a special focus on their spatial and temporal characteristics. The associated atmospheric and ocean conditions are explored in section 4 . Section 5 examines the possible relationship between SAT SOMs and winter extreme events. The summary and concluding remarks are presented in section 6 .

\section{Methodology}

\section{a. Data}

We used the daily and monthly data for atmospheric and surface fields from the European Centre for Medium-Range Weather Forecasts (ECMWF) interim reanalysis (ERA-Interim) (Dee et al. 2011). They include surface air temperature (SAT), sea ice concentration (SIC), and sea surface temperature (SST) on a $1^{\circ}$ grid, and tropospheric air temperature and horizontal winds on a $2.5^{\circ}$ grid. In addition, daily data for surface downward longwave radiation and precipitable water were obtained from the National Centers for Environmental Prediction (NCEP)-Department of Energy (DOE) Reanalysis 2 product (NCEP-DOE R2; Kanamitsu et al.
2002) on Gaussian grids, which were regridded onto the same $2.5^{\circ}$ grid. Both ERA-Interim and NCEP-DOE R2 datasets used in this study cover the period from December 1979 to February 2019. We focus on the boreal winter, which refers to December-February (DJF; e.g., the winter of 1979 is for December 1979-February 1980), and all leap days were removed; thus, 40 boreal winters from 1979 to 2018 are analyzed in this study. The mean seasonal cycle at each grid was removed by subtracting the climatological daily (monthly) mean of 1979-2019 for each calendar day (month), and the long-term linear trend during the same period was then removed before further analyses since our focus is on the interannual and interdecadal variability. The case without the detrending showed similar SAT patterns but with more pronounced trends during 1979-2018 in their occurrence frequencies.

\section{b. Self-organizing maps}

The SOM approach is based on neural networks. It classifies the input data (i.e., the detrended daily winter SAT anomalies, defined as the deviations from the 1979-2018 mean for each calendar day) in this study into user-specified number of clusters (Kohonen 2001). The SOMs train all the input data simultaneously, rather than merging clusters in the previous step as other clustering methods do (Kohonen 2001). SOM analysis has been widely used to identify atmospheric teleconnection patterns (e.g., Johnson and Feldstein 2010; Yuan et al. 2015; Gervais et al. 2016; Lee et al. 2017; Loikith et al. 2019). Unlike empirical orthogonal function analysis, the pattern of a specific meteorological variable on each day can be assigned to a certain SOM, which would enable us to investigate the occurrence frequency of each SOM for the whole winter season (Yuan et al. 2015), together with their interannual or interdecadal variability. Another important difference is that the EOF approach requires the SAT anomaly values represented by an EOF mode to be temporally correlated between two different regions with significant loading but orthogonal with other EOF modes; while the SOM approach identifies the SAT anomaly patterns more holistically without those requirements, so it may identify different patterns from those using EOF or other traditional methods. For example, the sign of the SAT anomalies over two regions may be temporally correlated in a SOM pattern (e.g., one region has cold SAT while the other has warm SAT) but the SAT anomaly values over those two regions may be temporally uncorrelated. This difference is important for SAT analyses. For example, the SAT values of a polar airmass and that of a subtropical airmass are usually uncorrelated, but when the polar airmass moves equatorward in 
one location (e.g., North America) while the subtropical airmass moves poleward in another location (e.g., Eurasia) at the same time as required by atmospheric continuity or mass conservation, the signs of the SAT anomalies from these two regions will be temporally anticorrelated but the actual SAT anomaly values will be temporally uncorrelated as they come from the two uncorrelated air masses. The SOM would be able to detect such patterns while the EOF may miss them.

In this study, we performed SOM analyses using the MATLAB software with SOM Toolbox version 2.0 (see more details at http://www.cis.hut.fi/projects/somtoolbox/ about). The first important step in performing SOM analysis is to determine the number of SOMs, which is usually a matter of subjective choice that prefers a moderate size. Thus, there is a need to strike a balance between the number of SOMs that can capture the details of the actual patterns sufficiently and the number that differs from each other physically. The number of SOMs was tested for different grid sizes from $2(1 \times 2)$ to $50(5 \times 10)$. To help quantify the dissimilarity among the SOM patterns, we computed the Euclidian distance $d$ between two SOMs following Lee et al. (2017): $d(r, s)=\sqrt{2 n_{r} n_{s} /\left(n_{r}+n_{s}\right)}\left\|\bar{x}_{r}-\bar{x}_{s}\right\|_{2}$, where $n_{r}$ and $n_{s}$ are the number of matching days (i.e., best match units) for SOM $r$ and $s$, respectively, and $\bar{x}_{r}$ and $\bar{x}_{s}$ are centroid SAT patterns of SOM $r$ and $s$, respectively. The Euclidean distances between all pairs of the SOMs were calculated and their average is shown in Fig. 1a [e.g., there are 6 pairs for 4 $(2 \times 2)$ SOMs]. A large distance means that the SOM patterns are different, a desired property. We also calculated the pattern correlation between the daily SAT anomaly field for any given day and its best-matching SOM and averaged it over all days to derive the mean pattern correlation shown in Fig. 1a. A high correlation indicates that the SOMs can represent the SAT daily patterns well, again another desired property. As shown in Fig. 1a, the mean Euclidian distance between two patterns decreases while the mean pattern correlation increases slowly from $4 \times 5$ to $5 \times 10$ SOMs, implying that the SOMs are somewhat insensitive to these selected numbers within this range. In addition, the Buishand $U$ test (Buishand 1984) and the Mann-Kendall test were applied to the series of the mean pattern correlation (black line in Fig. 1a) to determine the optimal SOM size as the break point, which was detected around $4 \times 4$ to $4 \times 6$ SOMs, respectively (Figs. 1b,c). Based on these analyses, the $4 \times 5$ SOMs are chosen in this study. Our tests showed that using smaller numbers of SOMs (e.g., $4 \times 4)$ than $4 \times 5$ would merge some of the patterns while using larger numbers (e.g., $4 \times 6$ ) could capture the essential aspects of the $4 \times 5$ SOMs but with more duplicate patterns. As shown later, the $4 \times 5$ SOMs also match the leading EOF patterns (of winter
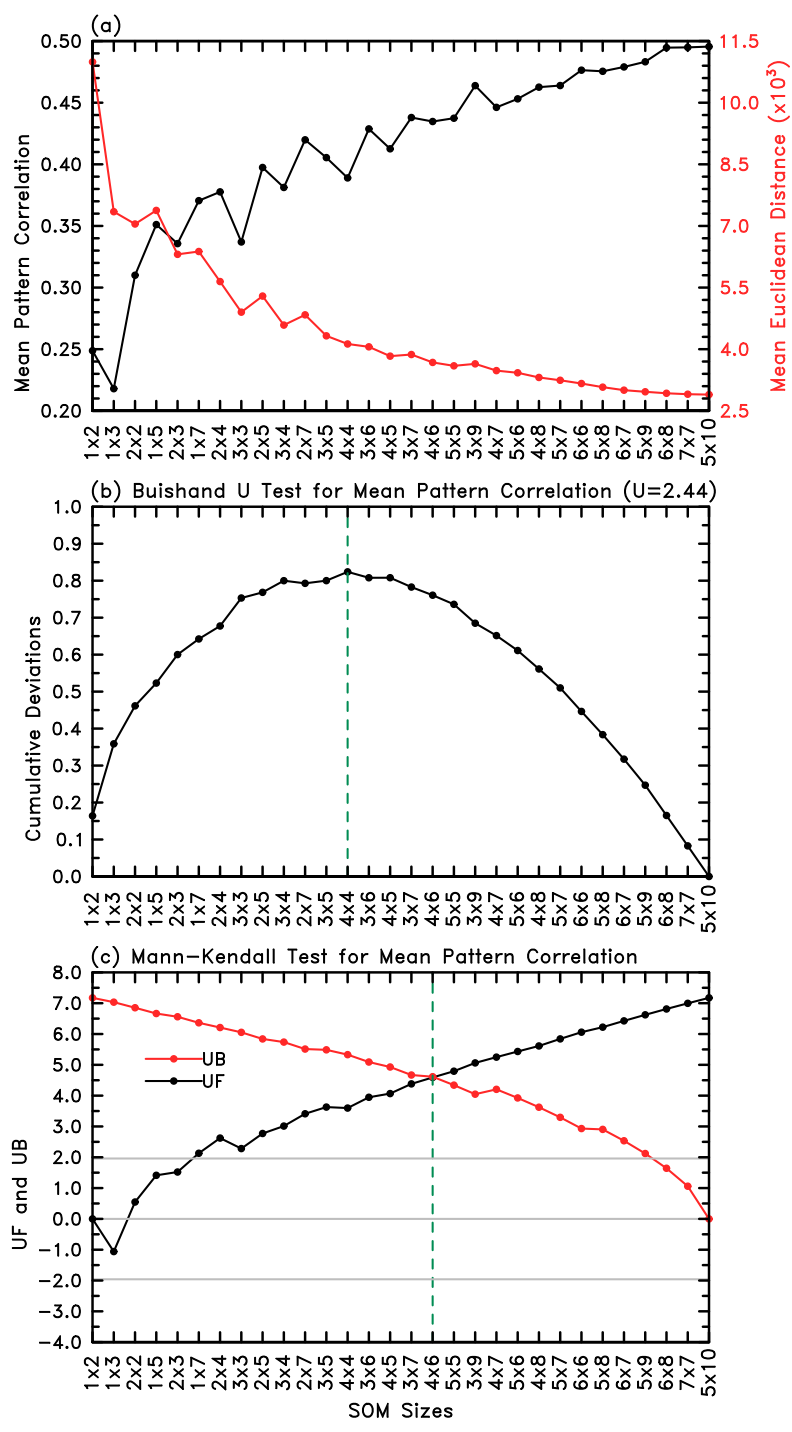

FIG. 1. (a) The mean Euclidean distances $\left(\times 10^{3}\right.$; red line) between each pair of SOM patterns and the mean pattern correlations (black line) between the winter daily surface air temperature (SAT) anomaly fields in the extratropical Northern Hemisphere (north of $20^{\circ} \mathrm{N}$ ) and the best-matching SOM patterns as a function of the specified number of SOMs from $(1 \times 2)$ to $(5 \times 10)$. (b) The Buishand $U$ test and (c) the Mann-Kendall test for the mean pattern correlations. The green dashed vertical line in (b) and (c) indicates the location of the break point.

monthly SAT anomalies) well, which provides another justification. Our tests also showed that the three basic spatial patterns revealed by the SOMs (discussed below) are evident and similar with many other choices of SOM dimensions (e.g., $7 \times 1)$.

In addition, to verify the leading SAT patterns revealed by the SOM, an EOF analysis was also performed on detrended monthly SAT anomalies north of $20^{\circ} \mathrm{N}$ during winters of 1979-2018 (i.e., $3 \times 40=$ 120 months in total), as the monthly mean anomalies 
result from the averaging of the daily SAT anomalies. Both daily and monthly SAT anomalies were weighted by the square root of the cosine of latitude in our analyses to account for the area difference among grid boxes. Note that the EOF patterns reveal the leading orthogonal modes in the winter monthly mean SAT anomalies, whereas the SOM patterns reveal the preferred occurrence patterns of the daily SAT anomalies. Therefore, the EOF patterns may help us explore the intrinsic connection between daily and monthly SAT patterns, despite the key difference between the two methods. For the SOM analysis, detrended daily SAT anomalies north of $20^{\circ} \mathrm{N}$ for all winter days (i.e., $90 \times 40=3600$ days in total) were used to detect the leading winter daily SAT patterns over the extratropical NH. Consequently, detrended anomaly composites in other related variables averaged over all matching days for the corresponding SAT SOM would allow us to explore the associated atmospheric and ocean conditions. The statistical significance of these anomaly composites was estimated using the two-tailed Student's $t$ test. Following Yuan et al. (2015), the degree of freedom $N_{\text {dof }}$ for the Student's $t$ test is defined as $N_{\text {dof }}=N_{\text {som }} / \tau$, where $N_{\text {som }}$ is the number of matching days for a specific SAT SOM, and $\tau$ is the $e$-folding time scale. To obtain the $e$ folding time scale for each SAT SOM, the projection time series $P(t)$ is computed by projecting daily SAT anomalies $T$ onto the SAT SOM pattern $T^{*}$ following Johnson and Feldstein (2010):

$$
P(t)=\frac{\sum_{i} \sum_{j} T^{\prime}\left(\lambda_{i}, \theta_{j}, t\right) T^{*}\left(\lambda_{i}, \theta_{j}\right) \cos \theta_{j}}{\sum_{i} \sum_{j}\left[T^{*}\left(\lambda_{i}, \theta_{j}\right)\right]^{2} \cos \theta_{j}}
$$

where $\lambda_{i}\left(\theta_{j}\right)$ is the longitude (latitude) at zonal (meridional) grid point $i(j)$, and $t$ is time. The $e$-folding time scale $(\tau)$ is defined as the time over which the autocorrelation of $P(t)$ decays to $1 / e$.

\section{SAT SOM patterns}

\section{a. Spatial characteristics}

Figure 2 shows the $4 \times 5$ SOMs of the winter detrended daily SAT anomalies over the extratropical NH. The SAT SOMs located in the upper left and lower right corners show a significant concurrence of winter SAT anomalies of the same sign over North America (NA) and northern Eurasia (NE) (referred to as the NANE pattern), while the Arctic region (especially the Baffin Bay) and North Africa see SAT anomalies of the opposite sign. Therefore, the NANE pattern reflects a tripole structure of winter SAT anomalies over Eurasia, the Arctic, and North America. On the other hand, the
SAT SOMs located in the upper right and lower left corners show a dipole pattern over North America and the Bering Sea (BS) that resembles the NANE pattern but with larger magnitudes over the two regions (referred to as the NABS pattern), whereas central Eurasia (CE) sees SAT anomalies of the same sign as the Bering Sea. In addition, some SAT SOMs in the center (e.g., SOM 10, 11, 14, and 15) also exhibit a tripole pattern with the SAT anomalies over the Kara Sea (KS) and the coastal Eurasia around the Arctic being opposite to those over East Asia (EA) and Canada, and this pattern is mostly associated with the dipole anomaly structure between the Kara Sea and East Asia (referred to as the KSEA pattern). To better characterize these patterns, we further divided the $4 \times 5$ SOMs into six distinct winter SAT teleconnection patterns based on the organization of the SOMs: the $\mathrm{NA}^{-} \mathrm{NE}^{-}$(SOM 1, 2, 5, 6, and 7), $\mathrm{NA}^{+} \mathrm{NE}^{+}$(SOM 16, 18, 19, and 20), $\mathrm{NA}^{-} \mathrm{BS}^{+}$(SOM 13 and 17 ), $\mathrm{NA}^{+} \mathrm{BS}^{-}$(SOM 4, 8, and 12), $\mathrm{KS}^{+} \mathrm{EA}^{-}$ (SOM 9, 10, 11,14, and 15), and $\mathrm{KS}^{-} \mathrm{EA}^{+}$(SOM3) patterns, where the plus (minus) sign indicates positive (negative) SAT anomalies while NA stands for North America, NE for northern Eurasia, BS for the Bering Sea, KS for the Kara Sea, and EA for East Asia (see Fig. 3 for their exact definitions). Accordingly, each of the SOM patterns can be assigned to a particular SAT teleconnection pattern, which includes two polarities of nearly opposite sign. Here, we defined the $\mathrm{NA}^{-} \mathrm{NE}^{-}$ $\left(\mathrm{NA}^{+} \mathrm{NE}^{+}\right), \mathrm{NA}^{-} \mathrm{BS}^{+}\left(\mathrm{NA}^{+} \mathrm{BS}^{-}\right)$, and $\mathrm{KS}^{+} \mathrm{EA}^{-}\left(\mathrm{KS}^{-}\right.$ $\mathrm{EA}^{+}$) patterns as positive (negative) phases for the NANE, NABS, and KSEA patterns, respectively, even though the spatial patterns may not be exactly the opposite between the two phases.

Figure 3 shows the composites of winter SAT anomalies for each SAT pattern. For the NANE-like SOMs, the $\mathrm{NA}^{-} \mathrm{NE}^{-}$pattern corresponds to concurring colder SAT over North America and northern Eurasia, while warmer SAT is seen over the Bering Sea, Baffin Bay, and midlatitude Eurasia (Fig. 3a). The $\mathrm{NA}^{+} \mathrm{NE}^{+}$pattern resembles the $\mathrm{NA}^{-} \mathrm{NE}^{-}$pattern but with nearly opposite signals, and the warmer SAT over North America is relatively larger in magnitudes than northern Eurasia (Fig. 3b). For the NABS-like SOMs (Figs. 3d,e), colder (warmer) SAT is centered over North America while warmer (colder) SAT is located over the Bering Sea and central Eurasia for the $\mathrm{NA}^{-} \mathrm{BS}^{+}\left(\mathrm{NA}^{+} \mathrm{BS}^{-}\right)$ pattern. For the KSEA-like SOMs, the $\mathrm{KS}^{+} \mathrm{EA}^{-}$pattern is characterized by warmer SAT over the Kara Sea and coastal Eurasia around the Arctic and colder SAT over East Asia and Canada (Fig. 3g), while the $\mathrm{KS}^{-} \mathrm{EA}^{+}$ pattern shows the opposite pattern (Fig. 3h). It can be seen that most of the SOM patterns (i.e., daily patterns) resemble one of the leading EOF patterns (i.e., monthly 

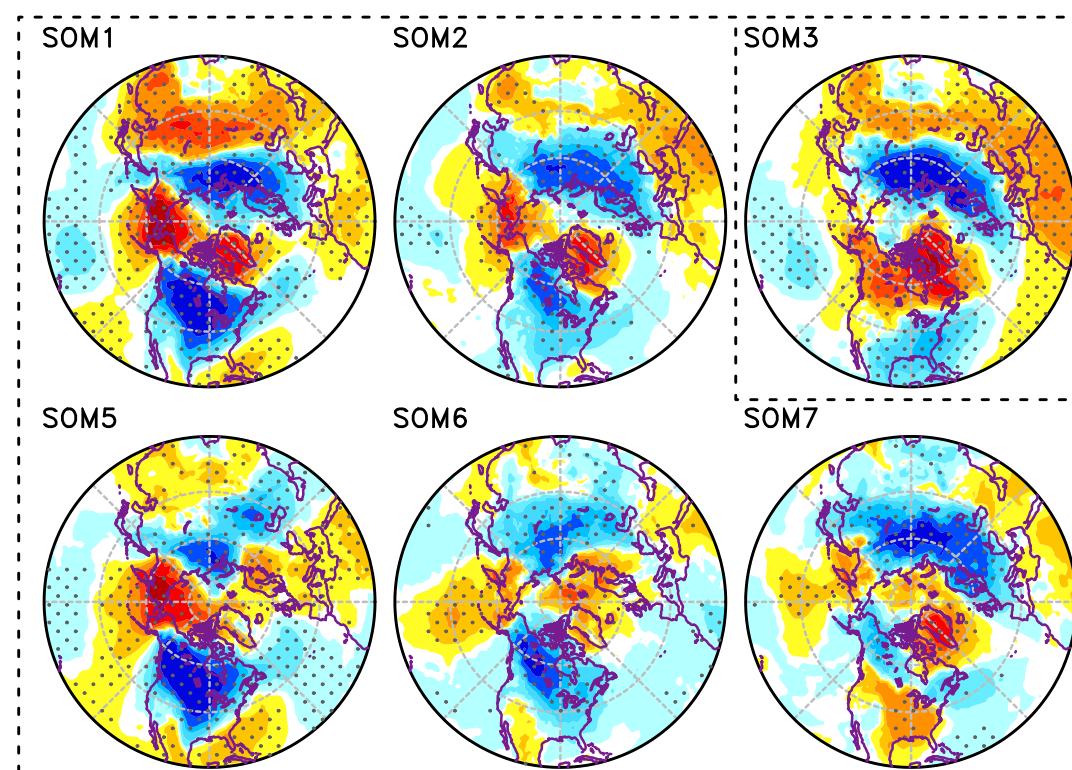

SOM 6
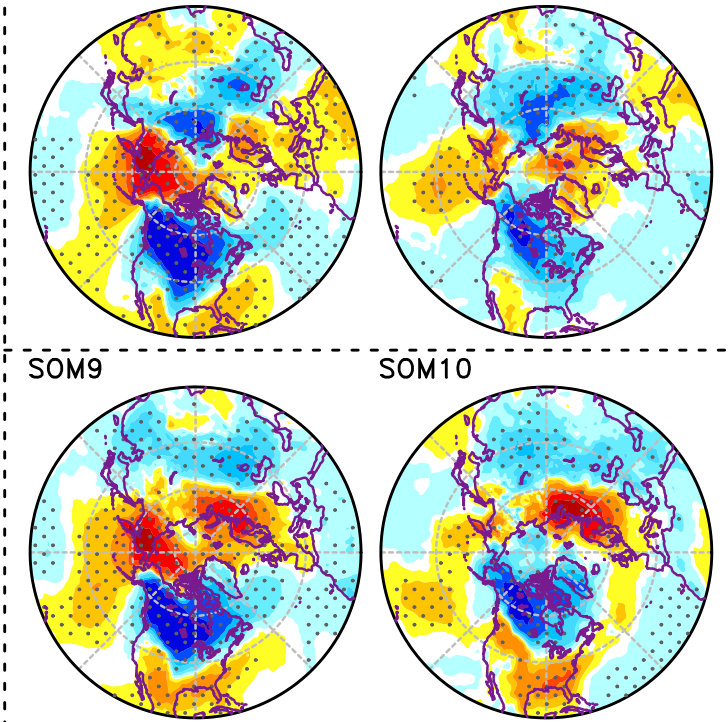

'S̄ōM̄
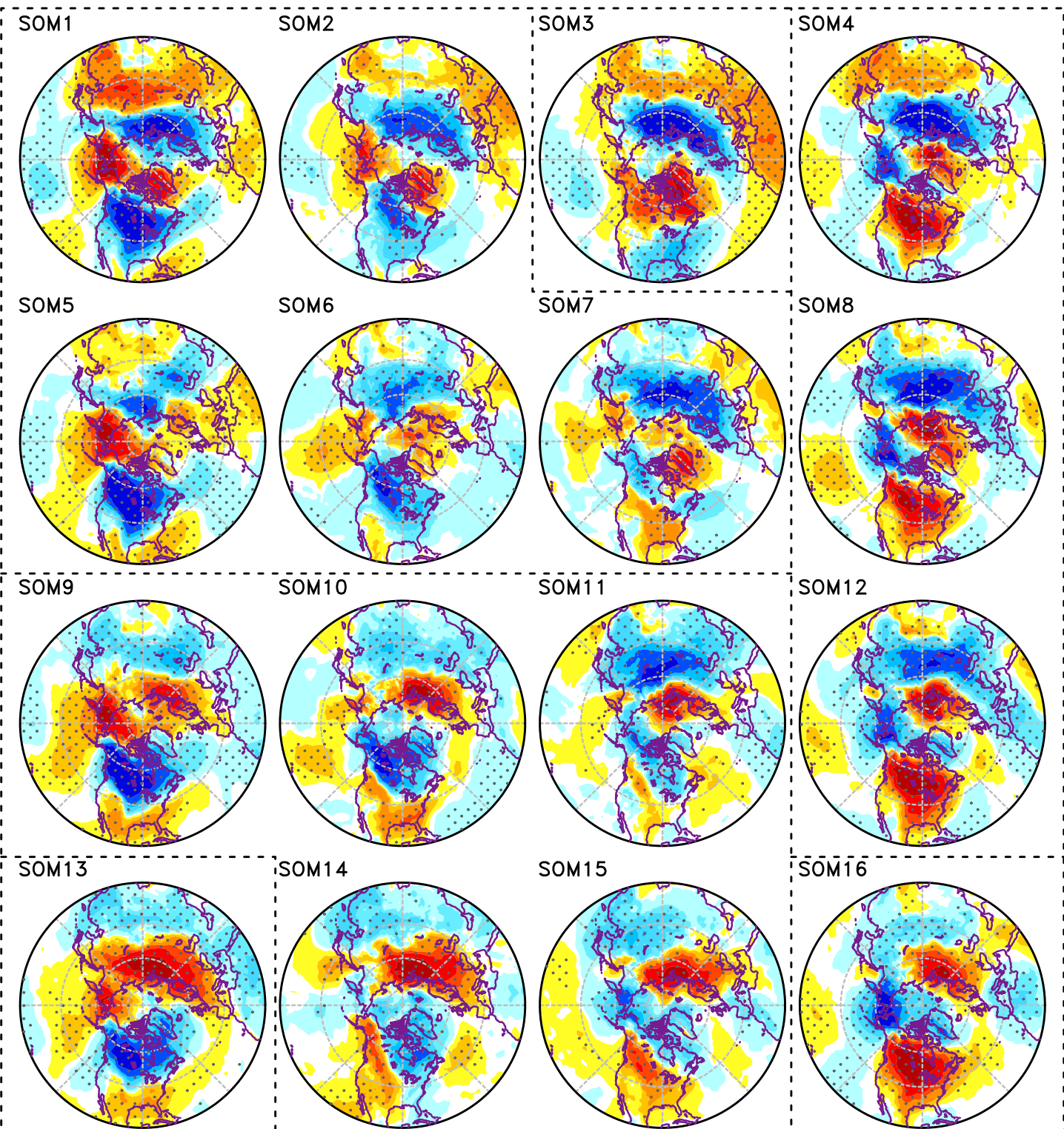

SOM 10
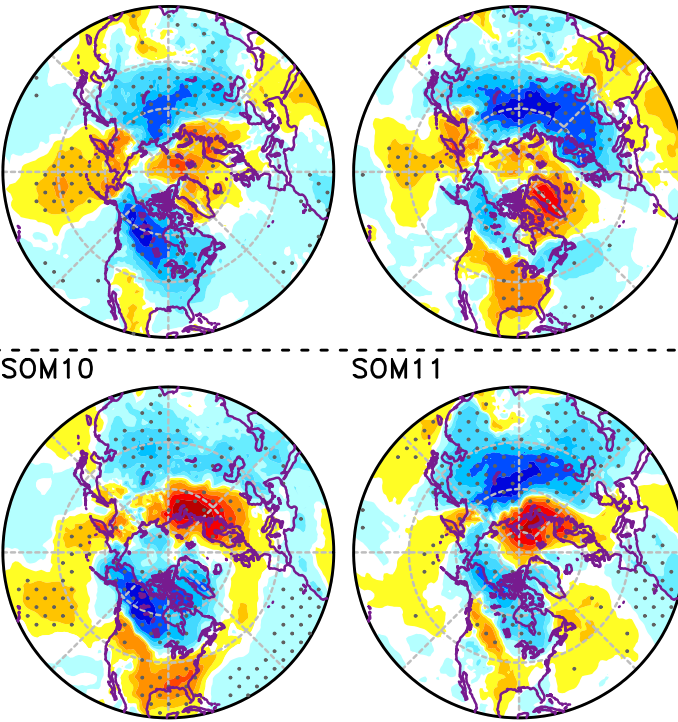

S̄OM̄ī
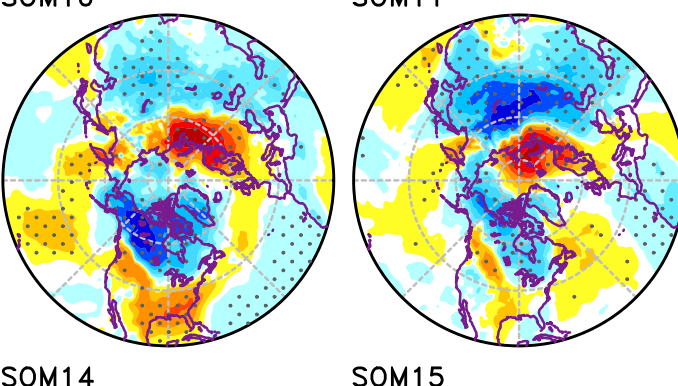

SOM15
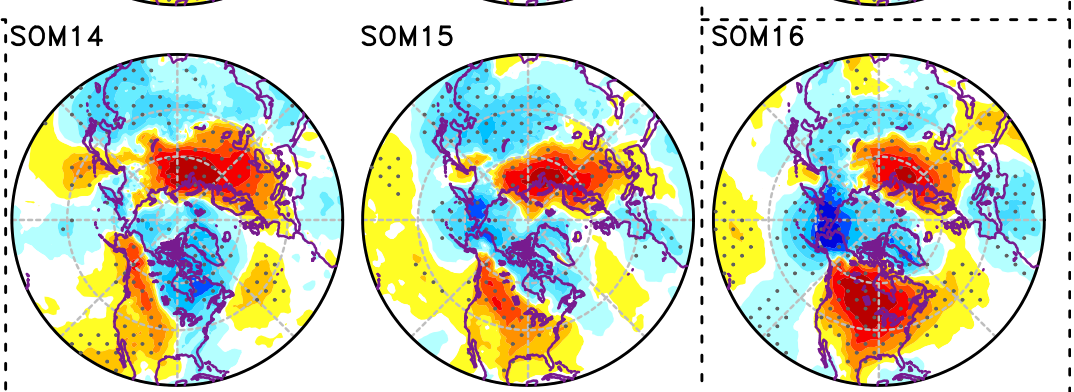

SOM 17

\section{SOM̄is}

sōin 19
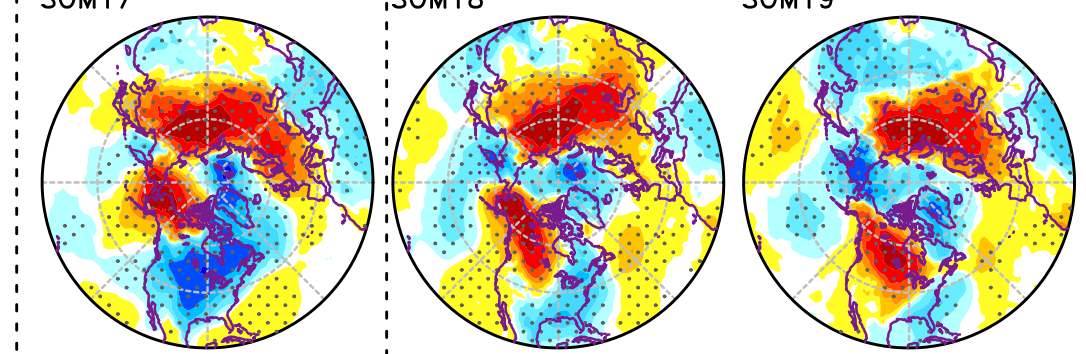

SOM20
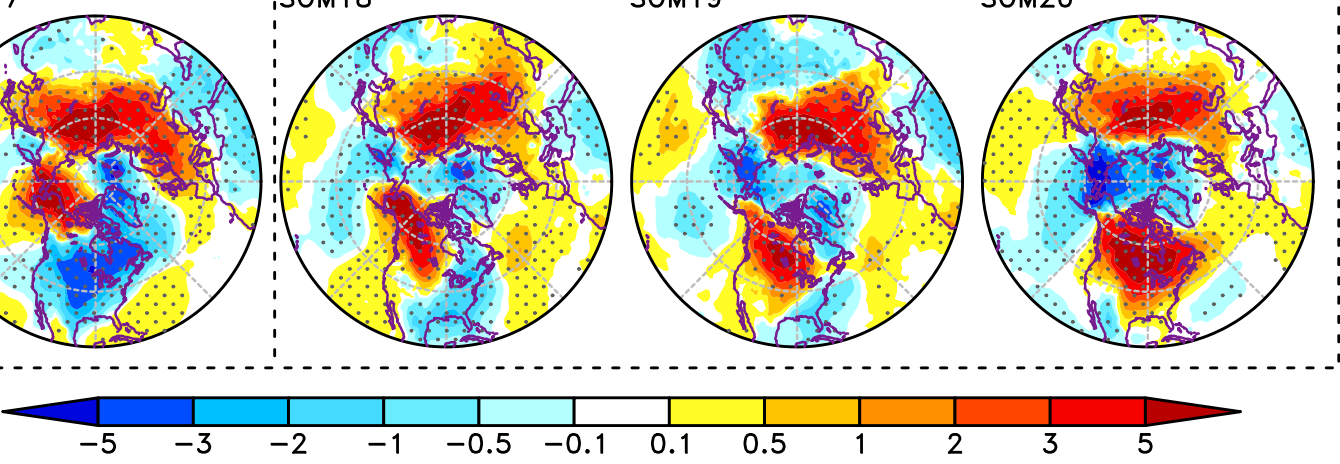

FIG. 2. The $4 \times 5$ SOM matrix of linearly detrended winter daily surface air temperature (SAT) anomalies (K) over $20^{\circ}-$ $90^{\circ} \mathrm{N}$ based on ERA-Interim data from 1979-2019. SOM patterns 1-20 are located from the top left to the bottom right. Stippling indicates the anomalies are statistically significant at the $95 \%$ confidence level based on the Student's $t$ test. All SOMs are divided into six groups shown by dashed boxes. 
(a) SOMs (NA-NE-, 21.53\%)

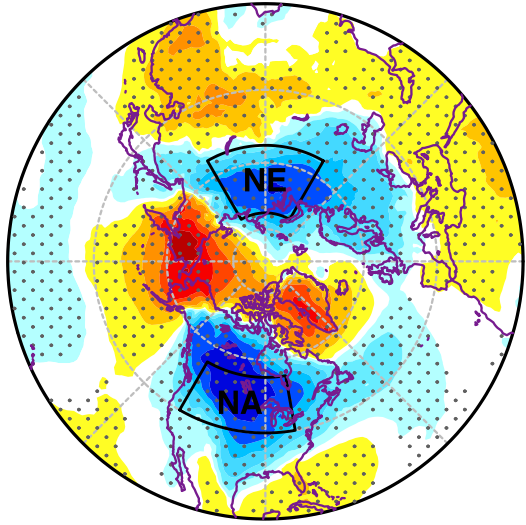

(b) SOMs (NA+NE+, 24.83\%)

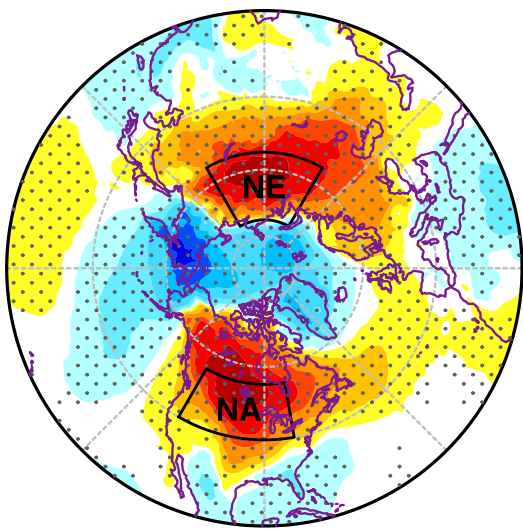

(c) EOF1 (NANE, $18.31 \%$ )

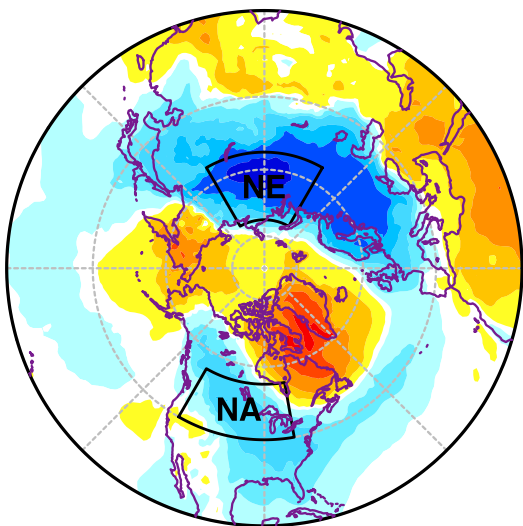

(d) SOMs (NA-BS+, 12.17\%)

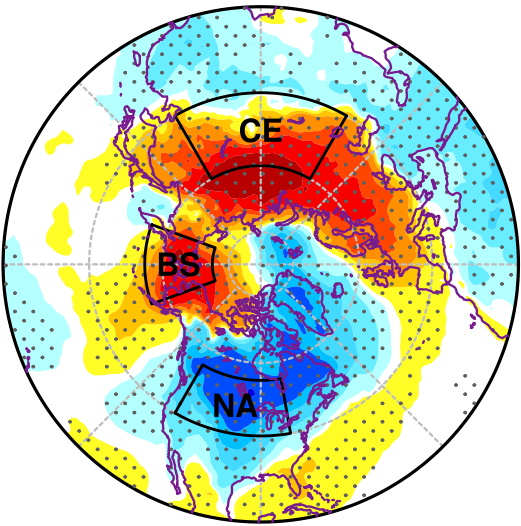

(e) SOMs (NA+BS-, 17.00\%)

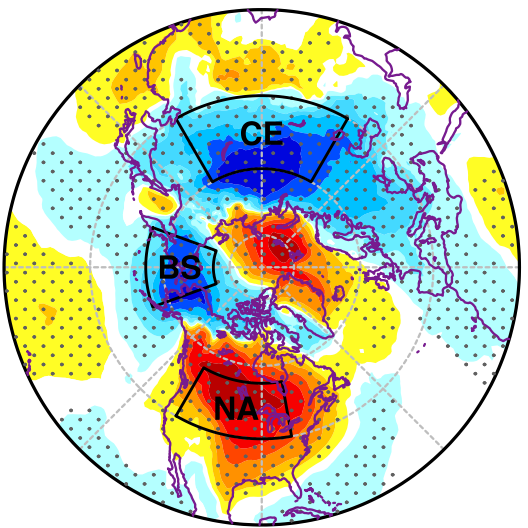

(f) EOF2 (NABS, $12.12 \%$ )

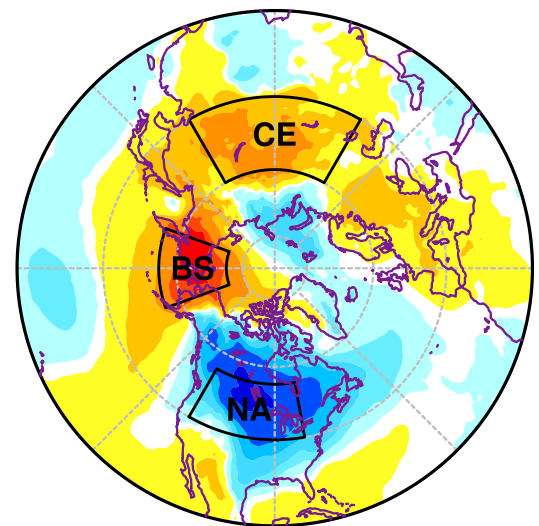

(g) SOMs (KS+EA-, 16.69\%)

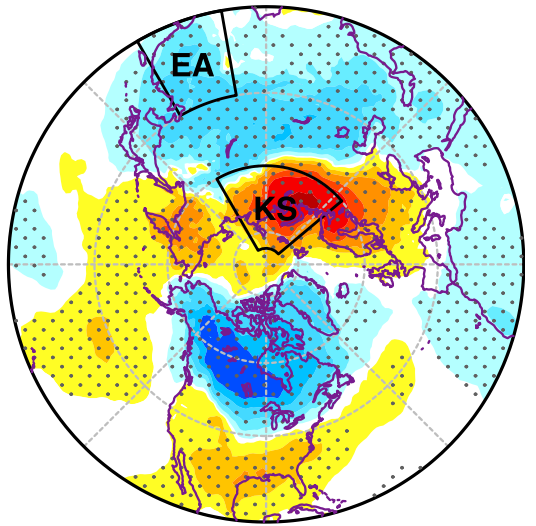

(h) SOMs (KS-EA+, 7.78\%)

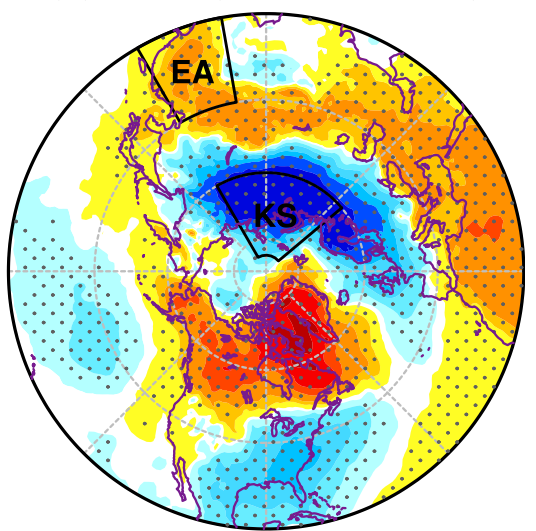

(i) EOF3 (KSEA, 10.03\%)

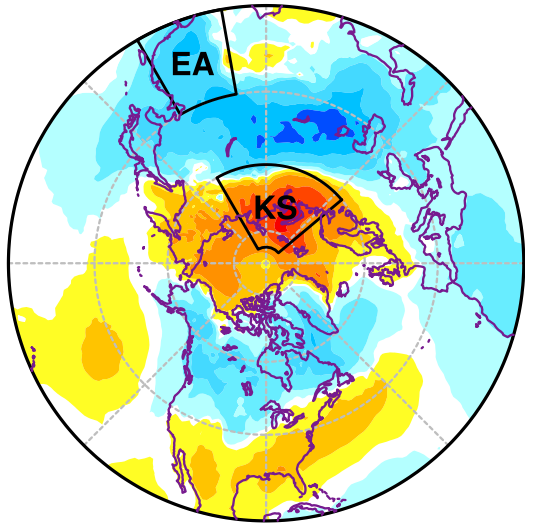

\section{$\begin{array}{llllllllllll} & & & \mid & & & & \mid & & \mid & & \\ -5 & -3 & -2 & -1 & -0.5 & -0.1 & 0.1 & 0.5 & 1 & 2 & 3 & 5\end{array}$}

FIG. 3. Composites of linearly detrended winter daily SAT anomalies (K) over $20^{\circ}-90^{\circ} \mathrm{N}$ in all matching days for the corresponding SAT SOMs based on ERA-Interim data from 1979-2019: the (a),(b) NANE, (d),(e) NABS, and (g),(h) KSEA patterns. Stippling indicates the anomalies are statistically significant at the $95 \%$ confidence level based on the Student's $t$ test. Also shown are the spatial patterns of the three leading EOFs of linearly detrended winter monthly SAT anomalies over $20^{\circ}-90^{\circ} \mathrm{N}$ : (c) EOF1 (NANE pattern), (f) EOF2 (NABS pattern), and (i) EOF3 (KSEA pattern). The occurrence frequency for SOMs and explained variance (\%) for EOFs are shown in parentheses. The black lines outline the North America $\left(\mathrm{NA} ; 80^{\circ}-120^{\circ} \mathrm{W}, 40^{\circ}-55^{\circ} \mathrm{N}\right)$, northern Eurasia $\left(\mathrm{NE} ; 60^{\circ}-120^{\circ} \mathrm{E}, 55^{\circ}-75^{\circ} \mathrm{N}\right), \mathrm{Bering}$ Sea $\left(\mathrm{BS} ; 160^{\circ} \mathrm{E}-160^{\circ} \mathrm{W}, 55^{\circ}-75^{\circ} \mathrm{N}\right)$, central Eurasia $\left(\mathrm{CE} ; 60^{\circ}-120^{\circ} \mathrm{E}, 40^{\circ}-60^{\circ} \mathrm{N}\right)$, Kara Sea $\left(\mathrm{KS} ; 40^{\circ}-120^{\circ} \mathrm{E}, 60^{\circ}-85^{\circ} \mathrm{N}\right)$, and East Asia $(\mathrm{EA}$; $\left.100^{\circ}-120^{\circ} \mathrm{E}, 20^{\circ}-40^{\circ} \mathrm{N}\right)$ regions used in our analyses. 
patterns) (Figs. 3c,f,i). Moreover, the $\mathrm{NA}^{-} \mathrm{BS}^{+}$and $\mathrm{KS}^{+} \mathrm{EA}^{-}$patterns are consistent with the previous findings of Kug et al. (2015), who obtained these two distinct SAT patterns using correlation analyses based on monthly reanalysis data. Thus, these results indicate that the leading monthly patterns of winter SAT anomalies may arise from occurrence frequencies of leading daily SAT patterns. This point is further discussed in section $3 \mathrm{~b}$.

We also notice that the largest SAT anomalies occur mainly over North America, Eurasia, and the Arctic region, rather than over the North Pacific and North Atlantic Ocean in the leading EOF and SOM patterns (Fig. 3). In other words, extreme cold or warm events tend to occur over North America and Eurasia, often simultaneously, while the SAT anomalies over the North Pacific and North Atlantic Ocean tend to be small. The relatively small SAT anomalies over the North Pacific and North Atlantic may result from two factors: 1) relatively stable SSTs can damp the SAT anomalies above them and 2) winds over these oceanic areas (south of $\sim 50^{\circ} \mathrm{N}$ ) tend to be more zonal and less meridional than over the continents for most of the SOMs (see Fig. 11 later). The strong (weak) meridional wind over land (oceans) may be related to the unstable (stable) location of the jet stream over the continents (oceans).

To further investigate the implications of the SAT patterns, Fig. 4 shows scatterplots of daily SAT anomalies averaged over selected regions for each pattern, and these selected regions see relatively larger SAT anomalies in the corresponding SOMs. Clearly, regionally averaged daily SAT anomalies agree well in the sign of the corresponding SAT composites (Fig. 3) for the majority of the matching days for each SAT pattern. For instance, the concurring colder SAT anomalies over North America and northern Eurasia appear in $72 \%$ (558 out of 775 days) of the matching days for $\mathrm{NA}^{-} \mathrm{NE}^{-}$like SOMs (Fig. 4a), while the opposite occurs in about $71 \%$ (634 out of 894 days) of the matching days for $\mathrm{NA}^{+} \mathrm{NE}^{+}$-like SOMs (Fig. 4b). Thus, the $\mathrm{NA}^{-} \mathrm{NE}^{-}$ $\left(\mathrm{NA}^{+} \mathrm{NE}^{+}\right)$pattern indicates that North America and northern Eurasia would experience colder (warmer) SAT simultaneously in some winter days. Similarly, the $\mathrm{NA}^{-} \mathrm{BS}^{+}\left(\mathrm{NA}^{+} \mathrm{BS}^{-}\right)$pattern indicates that belownormal (above-normal) winter daily SAT over North America is associated with warmer (colder) SAT over the Bering Sea (Figs. 4c,d), and the $\mathrm{KS}^{+} \mathrm{EA}^{-}\left(\mathrm{KS}^{-}\right.$ $\mathrm{EA}^{+}$) pattern indicates that below-normal (abovenormal) SAT over East Asia is associated with abovenormal (below-normal) SAT over the Kara Sea (Figs. 4e,f). However, the correlations between the values of daily SAT anomalies averaged over the two regions are quite small and insignificant for these patterns. This indicates that the daily SAT teleconnections among certain regions depicted by the SOMs represent only concurring signs of winter SAT anomalies, rather than relationships in magnitudes of the anomalies. This is different from the EOF patterns, which represent correlated anomaly values between two regions with large EOF coefficients.

\section{b. Temporal characteristics}

The number of matching days for each SOM pattern is given in Table 1 . The SOM20 $\left(\mathrm{NA}^{+} \mathrm{NE}^{+}\right)$pattern occurred most frequently $(10.22 \%)$ during the winters of 1979-2018, and the SOM1 $\left(\mathrm{NA}^{-} \mathrm{NE}^{-}\right)$, SOM3 (KS $\left.\mathrm{EA}^{+}\right)$, and SOM18 $\left(\mathrm{NA}^{+} \mathrm{NE}^{+}\right)$patterns follow with frequencies of $8.25 \%, 7.78 \%$, and $7.25 \%$, respectively. Overall, the NANE-like SOMs occurred most frequently (24.83\% for $\mathrm{NA}^{+} \mathrm{NE}^{+}$and $21.53 \%$ for $\mathrm{NA}^{-} \mathrm{NE}^{-}$; Figs. $3 a, b)$. Figure 5 shows the number of days for each SAT pattern per boreal winter. Considerable interannual and interdecadal variability exists in the occurrences of the SAT SOMs. Interannual variations of these patterns are even more pronounced and they contribute to unusual winter weather events over the midlatitude $\mathrm{NH}$ in the recent decades (e.g., Lu and Chang 2009; Jung et al. 2010; Yu and Zhang 2015; Baxter and Nigam 2015; Peng et al. 2018). For example, the 2009/10 extreme cold winter over North America, Northeast Asia, and Europe noticed previously (e.g., Cohen et al. 2010) may be largely attributed to the frequent occurrences of $\mathrm{KS}^{-} \mathrm{EA}^{+}$-like SOMs in this winter, which are closely related to the below-normal SAT over these regions (Fig. 3h). The severe 2013/14 cold winter across a large area of central-eastern North America examined previously (e.g., Yu and Zhang 2015; Baxter and Nigam 2015; Peng et al. 2018) may largely arise from the unusual frequent occurrences of $\mathrm{NA}^{-} \mathrm{NE}^{-}, \mathrm{NA}^{-}$ $\mathrm{BS}^{+}-$, and $\mathrm{KS}^{+} \mathrm{EA}^{-}$-like SOMs that are conducive to below-normal SAT over North America (Figs. 3a,d,g). Additionally, the concurrent "warm-west/cold-east" SAT anomalies over North America in this winter as reported previously (e.g., Singh et al. 2016; Peng et al. 2018) are likely associated with more frequent occurrences of $\mathrm{NA}^{-} \mathrm{NE}^{-}$and $\mathrm{NA}^{-} \mathrm{BS}^{+}$-like SOMs (Figs. 3a,d). These results imply that the DJF-mean SAT anomalies over a certain region of the midlatitude $\mathrm{NH}$ may arise from varying occurrence frequencies of distinct SOMs.

Following previous studies (e.g., Yuan et al. 2015; Lee et al. 2017), the $e$-folding time scale of each SOM is calculated using Eq. (1). It is found that all the SAT SOMs exhibit time scales ranging from 7 to 12 days (Table 1 ). The NANE, NABS, and KSEA-like SOMs have average $e$-folding time scales of 8,8 , and 9 days, respectively (Table 1). Overall, the winter SAT SOM patterns can predominantly last for about one week to 10 days.

Figure 6 shows the time series of the normalized occurrence frequency of the SOMs grouped by the three 
(a) NA-NE- SOMs

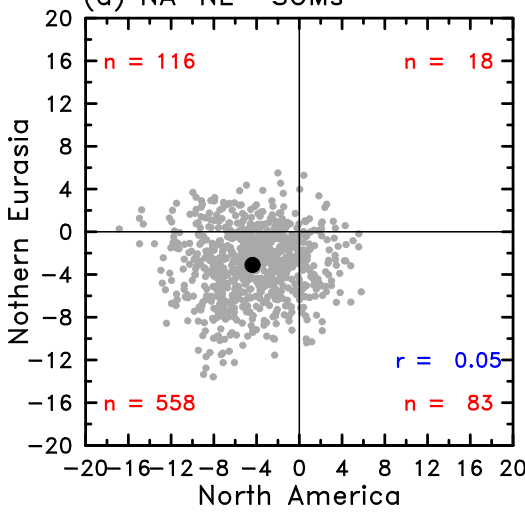

(b) $\mathrm{NA}+\mathrm{NE}+\mathrm{SOMS}$

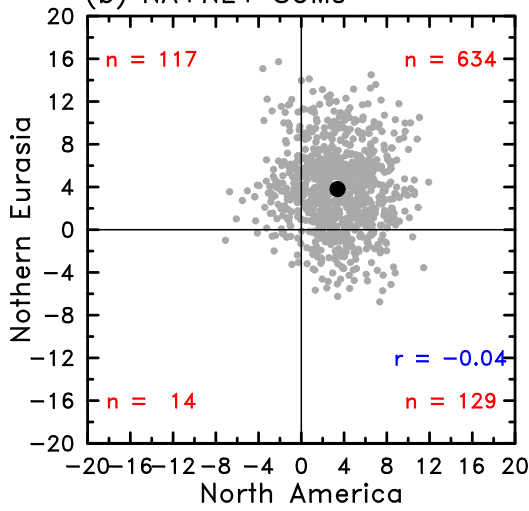

(c) NA-BS+ SOMs

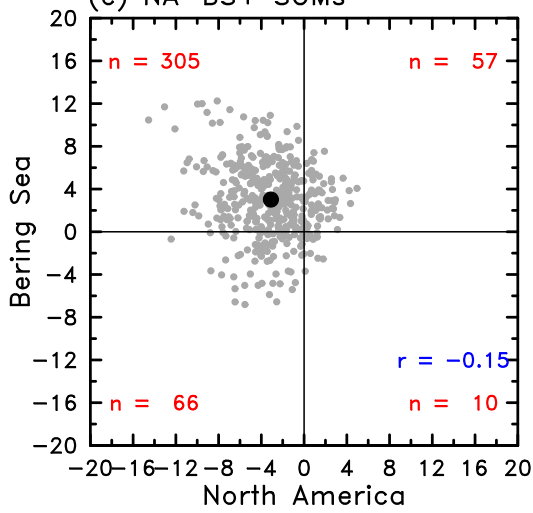

(d) NA+BS- SOMs

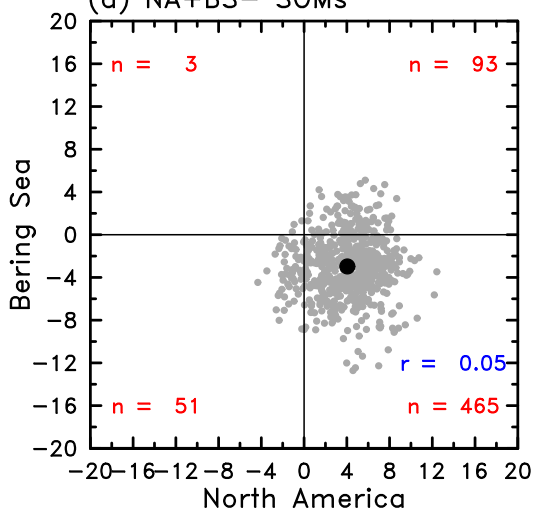

(e) $\mathrm{KS}+\mathrm{EA}-\mathrm{SOMS}$

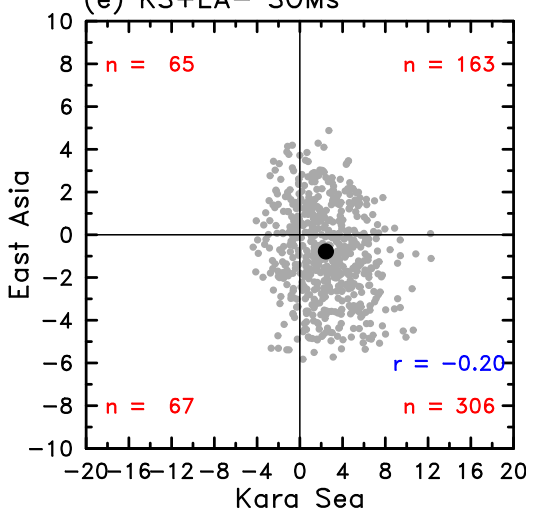

(f) $\mathrm{KS}-\mathrm{EA}+\mathrm{SOMs}$

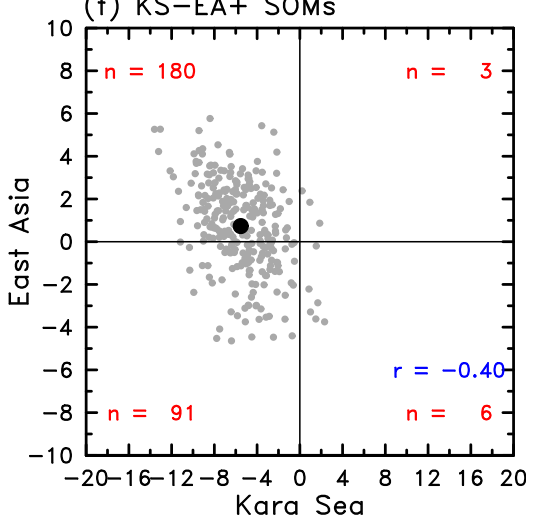

FIG. 4. Scatterplots of the detrended daily SAT anomalies (K) averaged over the (a),(b) NA ( $x$ axis) and NE ( $y$ axis) for the NANE-like SOMs, (c), (d) NA ( $x$ axis) and BS ( $y$ axis) for the NABS-like SOMs, and (e),(f) KS ( $x$ axis) and EA ( $y$ axis) for the KSEA-like SOMs. See Fig. 3 for the definitions of the regions. Each gray dot denotes a matching day for the corresponding SOMs, and the black dot indicates the average SAT anomalies. The number of days in each quadrant and the correlation coefficient are also given at the corners in red and blue, respectively.

SAT teleconnection patterns with two phases, together with the DJF-mean normalized principal components (PCs) of the corresponding EOF (Fig. 3). Since the Arctic warming has accelerated rapidly since the late 1990s (e.g., Kug et al. 2015), their linear trends from 1998 to 2018 are also shown in Fig. 6. The correlations between the SOM frequency and the corresponding PC are mostly significant at the $99 \%$ confidence level based on Student's $t$ test (except for $\mathrm{NA}^{-} \mathrm{BS}^{+}$and $\mathrm{KS}^{-} \mathrm{EA}^{+}$ patterns; Fig. 6), suggesting that the two time series match reasonably well. Overall, the positive phase of each SAT pattern shows an increasing trend since 1998

TABLE 1. The number of matching days and the $e$-folding time scale $\tau$ (days) for each SOM pattern of winter surface air temperature (SAT) over the Northern Hemisphere $\left(20^{\circ}-90^{\circ} \mathrm{N}\right)$.

\begin{tabular}{|c|c|c|c|c|c|}
\hline SOM No. (pattern) & Matching days & $\tau$ & SOM No. (pattern) & Matching days & $\tau$ \\
\hline $\operatorname{SOM} 1\left(\mathrm{NA}^{-} \mathrm{NE}^{-}\right)$ & $297(8.25 \%)$ & 7 & SOM $11\left(\mathrm{KS}^{+} \mathrm{EA}^{-}\right)$ & $127(3.53 \%)$ & 8 \\
\hline $\operatorname{SOM} 2\left(\mathrm{NA}^{-} \mathrm{NE}^{-}\right)$ & $96(2.67 \%)$ & 9 & SOM $12\left(\mathrm{NA}^{+} \mathrm{BS}^{-}\right)$ & $165(4.58 \%)$ & 7 \\
\hline SOM $3\left(\mathrm{KS}^{-} \mathrm{EA}^{+}\right)$ & $280(7.78 \%)$ & 12 & SOM $13\left(\mathrm{NA}^{-} \mathrm{BS}^{+}\right)$ & $194(5.39 \%)$ & 9 \\
\hline SOM $4\left(\mathrm{NA}^{+} \mathrm{BS}^{-}\right)$ & $235(6.52 \%)$ & 8 & SOM $14\left(\mathrm{KS}^{+} \mathrm{EA}^{-}\right)$ & $88(2.44 \%)$ & 10 \\
\hline SOM $5\left(\mathrm{NA}^{-} \mathrm{NE}^{-}\right)$ & $208(5.78 \%)$ & 7 & SOM $15\left(\mathrm{KS}^{+} \mathrm{EA}^{-}\right)$ & $101(2.81 \%)$ & 8 \\
\hline SOM $6\left(\mathrm{NA}^{-} \mathrm{NE}^{-}\right)$ & $96(2.67 \%)$ & 7 & $\operatorname{SOM} 16\left(\mathrm{NA}^{+} \mathrm{NE}^{+}\right)$ & $174(4.83 \%)$ & 7 \\
\hline SOM $7\left(\mathrm{NA}^{-} \mathrm{NE}^{-}\right)$ & $78(2.17 \%)$ & 10 & SOM $17\left(\mathrm{NA}^{-} \mathrm{BS}^{+}\right)$ & $244(6.78 \%)$ & 8 \\
\hline SOM $8\left(\mathrm{NA}^{+} \mathrm{BS}^{-}\right)$ & $212(5.89 \%)$ & 8 & $\operatorname{SOM} 18\left(\mathrm{NA}^{+} \mathrm{NE}^{+}\right)$ & $261(7.25 \%)$ & 8 \\
\hline SOM $9\left(\mathrm{KS}^{+} \mathrm{EA}^{-}\right)$ & $192(5.33 \%)$ & 7 & SOM $19\left(\mathrm{NA}^{+} \mathrm{NE}^{+}\right)$ & $91(2.53 \%)$ & 8 \\
\hline $\operatorname{SOM} 10\left(\mathrm{KS}^{+} \mathrm{EA}^{-}\right)$ & $93(2.58 \%)$ & 9 & $\operatorname{SOM} 20\left(\mathrm{NA}^{+} \mathrm{NE}^{+}\right)$ & $368(10.22 \%)$ & 7 \\
\hline
\end{tabular}




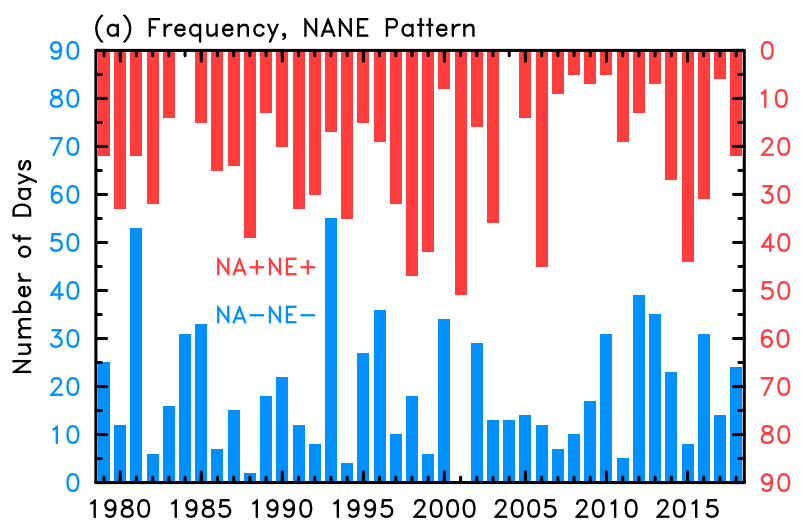

(b) Frequency, NABS Pattern

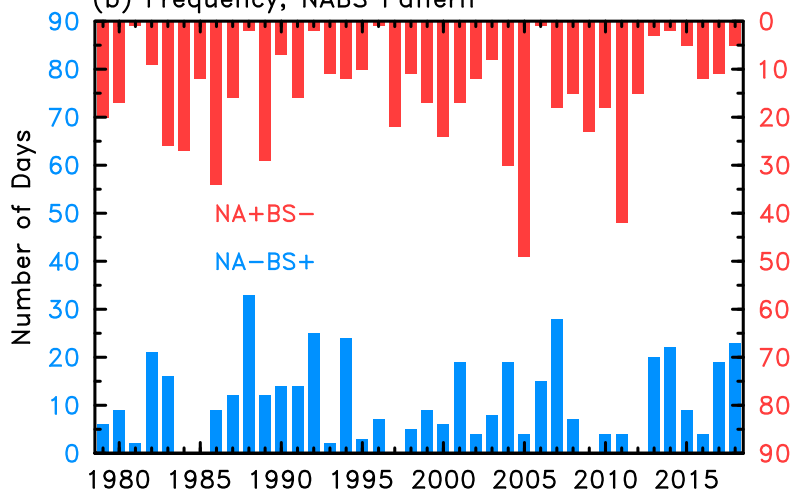

(c) Frequency, KSEA Pattern

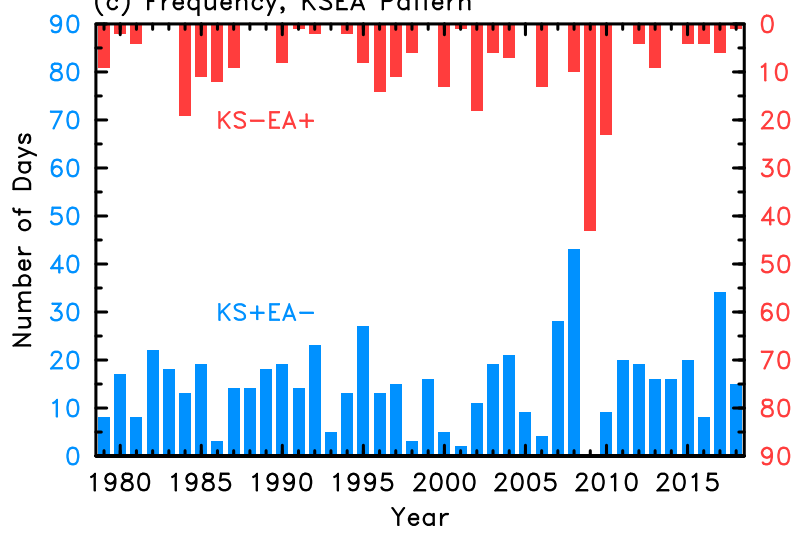

FIG. 5. The number of matching days for each SAT pattern per boreal winter: (a) $\mathrm{NA}^{-} \mathrm{NE}^{-}$(blue bars) and $\mathrm{NA}^{+} \mathrm{NE}^{+}$(red bars) patterns, (b) $\mathrm{NA}^{-} \mathrm{BS}^{+}$(blue bars) and $\mathrm{NA}^{+} \mathrm{BS}^{-}$(red bars) patterns, and (c) $\mathrm{KS}^{+} \mathrm{EA}^{-}$(blue bars) and $\mathrm{KS}^{-} \mathrm{EA}^{+}$(red bars) patterns. The left and right $y$ axes are for blue and red bars, respectively.

(Figs. 6a,c,e) while the negative phase shows the opposite (Figs. 6b,d,f). The NANE-like frequency time series exhibited an increasing (for $\mathrm{NA}^{-} \mathrm{NE}^{-}$) or a decreasing (for $\mathrm{NA}^{+} \mathrm{NE}^{+}$) trend while the corresponding $\mathrm{PC1}$ only shows a slight trend (Figs. 6a,b). However, the frequency time series of the $\mathrm{NA}^{-} \mathrm{BS}^{+}$and $\mathrm{KS}^{+} \mathrm{EA}^{-}$patterns, as well as the corresponding PCs (i.e., PC2 and PC3, respectively), experienced an increasing trend since 1998 (Figs. 6c,e). The opposite is true for the $\mathrm{NA}^{+} \mathrm{BS}^{-}$ and $\mathrm{KS}^{-} \mathrm{EA}^{+}$patterns (Figs. 6d,f). Kug et al. (2015) identified two distinct patterns of warming Arctic and cooling North America or East Asia in the boreal winter during 1998-2013 based on monthly data from observations. Here, we show that these patterns can also be identified by the SOM approach using daily reanalysis data (i.e., the $\mathrm{NA}^{-} \mathrm{BS}^{+}$and $\mathrm{KS}^{+} \mathrm{EA}^{-}$patterns in our results). This indicates that the warm Arctic-cold continent pattern (Overland et al. 2011) may be a result of the increasing occurrence frequency of the $\mathrm{NA}^{-} \mathrm{BS}^{+}$ and $\mathrm{KS}^{+} \mathrm{EA}^{-}$-like SOMs.

In summary, the above results demonstrate that the interannual variations and interdecadal changes in winter SAT over the extratropical NH may arise from similar variations in the occurrence frequency of the related SAT SOMs.

\section{Associated atmospheric and ocean conditions}

\section{a. Atmospheric conditions}

In midlatitudes, most of the poleward heat transport occurs in the atmosphere (Czaja and Marshall 2006). The $\mathrm{NH}$ winter polar cold airmass mainly grows over the northern Eurasian continent and the Arctic Ocean and then flows toward the midlatitudes (Iwasaki et al. 2014). To illustrate the pathways of the anomalous warm or cold airmass for identifying the SAT teleconnection patterns, Fig. 7 shows the composites of $850-\mathrm{hPa}$ potential temperature $\theta_{850}$ and horizontal heat flux anomalies for each SAT pattern. Note that the climatological mean $\theta_{850}$ of $280 \mathrm{~K}$ for all matching days of each SAT pattern and over all winter days are also shown, following Iwasaki et al. (2014), who suggested that $\theta_{850}$ below $280 \mathrm{~K}$ typically represents the polar cold airmass. Clearly, the $\theta_{850}$ anomaly patterns agree well with the corresponding SAT SOMs. For the $\mathrm{NA}^{-} \mathrm{NE}^{-}$ pattern (Fig. 7a), anomalous warm air over the North Pacific Ocean and North Atlantic Ocean flows into the polar region crossing the line of $\theta_{850}=280 \mathrm{~K}$, while the original cold polar airmass flows southward over the North American and Eurasian continents. These movements of airmasses lead to warm SAT anomalies over the Bering Sea and Greenland but cold anomalies over North America and Eurasia. In contrast, for the $\mathrm{NA}^{+} \mathrm{NE}^{+}$pattern (Fig. 7b), warm air from lower latitudes moves into northern North America and Eurasia, while the cold polar airmass move southward over the Bering Sea and Greenland, causing warm SAT anomalies over North America and cold anomalies over the Bering Sea and Greenland. The anomalous heat transport associated with 

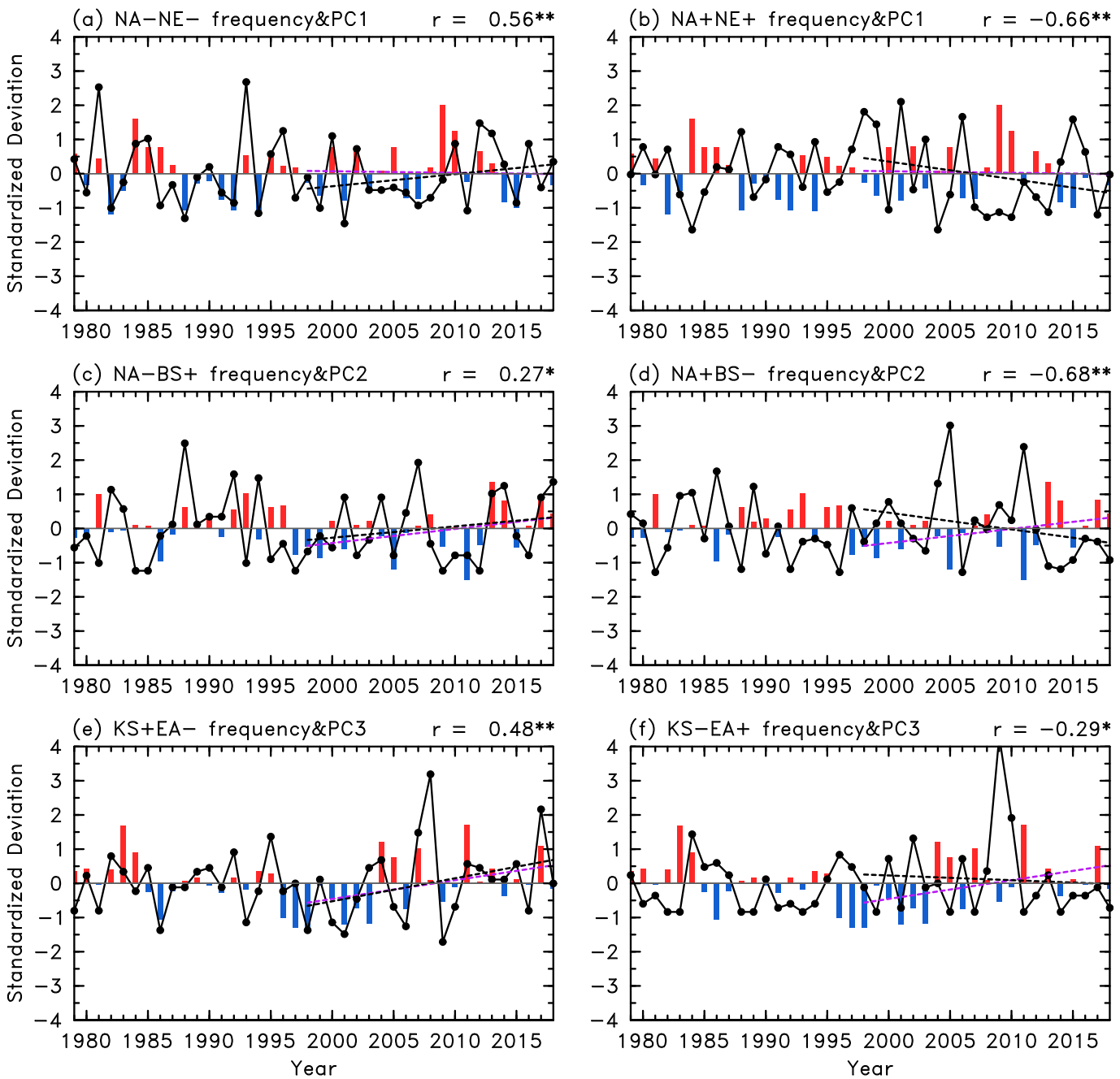

FIG. 6. Normalized occurrence frequencies (black solid line, in units of standard deviations) of the (a),(b) NANE-, (c),(d) NABS-, and (e),(f) KSEA-like SOMs. The color bars indicate DJF-mean normalized principal components of EOFs 1-3 in (a) and (b), (c) and (d), and (e) and (f), respectively. The straight lines represent the linear trends during 1998-2018 (black and purple dashed lines are for the corresponding frequency of SOMs and the corresponding PCs, respectively). The correlation coefficients between the PCs and occurrence frequencies of the corresponding SOMs are also given at the top-right corner of each panel. The asterisks and double asterisks indicate correlation coefficients at the $90 \%$ and $99 \%$ confidence levels of significance, respectively.

the NABS pattern (Figs. 7c,d) resembles the NANE pattern over the Bering Sea and North America but with opposite signals over the Eurasian continent. For the $\mathrm{KS}^{+} \mathrm{EA}^{-}$pattern (Fig. 7e), anomalous warm airstream locally generates around the coastal Eurasia and then intrudes into the Arctic region from Siberia, while the cold polar air mass breaks into East Asia and North America. The airmass movements are approximately the opposite for the $\mathrm{KS}^{-} \mathrm{EA}^{+}$pattern (Fig. 7f).

These results illustrate how the different patterns of the SAT anomalies over North America, Eurasia, and the Arctic region can result mainly from advection of warm air from the lower latitudes into high latitudes and the cold Arctic air breaking into the midlatitudes, often over North America, Eurasia, and the Bering Sea. While Fig. 7 only shows the simultaneous movements of the warm and cold airmasses and does not show which movement starts first, the mass conservation law requires that there must be an influx of warm air from the midlatitude into the Arctic when there is a break of the cold polar air into the midlatitudes, or vice versa. Presumably, the instability of the jet stream and polar vortex can trigger these meridional movements of the warm and cold airmasses on synoptic time scales, 


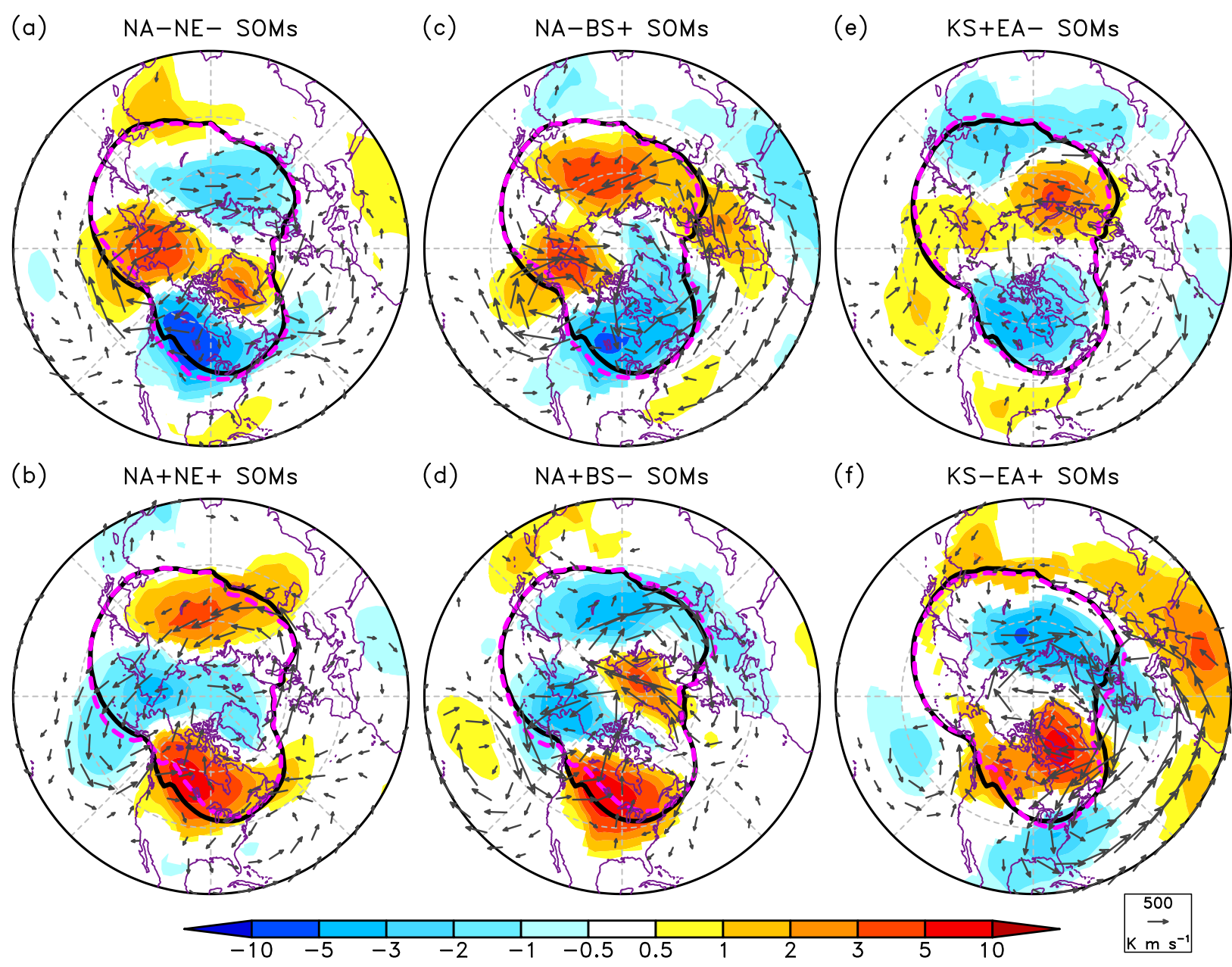

FIG. 7. Composites of winter 850 -hPa potential temperature $\theta$ anomalies (shading; $\mathrm{K}$ ) and horizontal heat fluxes $\mathbf{v} \theta$ anomalies (vectors; $\mathrm{K} \mathrm{m} \mathrm{s}^{-1}$ ) in all matching days for the corresponding SAT SOMs during 1979-2018: (a),(b) NANE, (c),(d) NABS, and (e),(f) KSEA patterns. The mean contours for $\theta=280 \mathrm{~K}$ averaged over all matching days of each pattern (purple dashed lines) and over all winter days (i.e., DJF climatology; black solid lines) are also shown. Only anomalies statistically significant at the $95 \%$ confidence level are plotted based on the Student's $t$ test.

leading to the pronounced SAT anomalies over North America, Eurasia, the Bering Sea, and other parts of the Arctic regions.

In addition, the meridional anomaly circulation appears to occur preferably over the Bering Strait, North America, Europe, and East Asia (Figs. 7 and 11). Note that the colder SAT over central Siberia in the $\mathrm{NA}^{-}$ $\mathrm{NE}^{-}$and $\mathrm{KS}^{-} \mathrm{EA}^{+}$patterns may be related to the prevailing westerly winds (which advect cold SAT anomalies from the west) rather than the anomalous southerly winds in this region. Since the movements of cold and warm airmasses are often associated with changes in the position of the jet stream, in Fig. 8 we explore the spatial correspondence between the mean positions of the maximum zonal wind at lower levels. As shown in Fig. 8, the mean position of the maximum $850-\mathrm{hPa}$ zonal wind is noticeably altered over the two storm-track regions during these SAT patterns, that is, over the eastern North Pacific for the NANE- and NABS-like SOMs (Figs. 8a,b), and over the eastern North Atlantic and Europe for the KSEA-like SOMs (Fig. 8c). However, the differences of the upper-level jet stream's mean position are small for most locations (not shown).

The warm and cold airmasses have different properties in terms of their temperature, humidity, and the associated longwave (LW) radiation that are appropriate for their original geographic locations. When they are advected to a different latitude, they cause anomalies (relative to the local climatology) not only in temperature, but also in water vapor content and LW radiation (Fig. 9), which are important for maintaining the SAT anomalies for some days (Zhang et al. 2011; Yu 
(a) $\mathrm{NA}-\mathrm{NE}-$ minus $\mathrm{NA}+\mathrm{NE}+$ SOMs

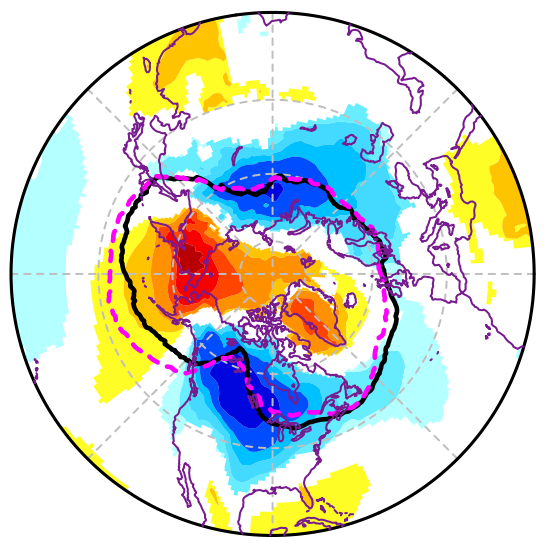

(b) NA-BS+ minus NA+BS- SOMs

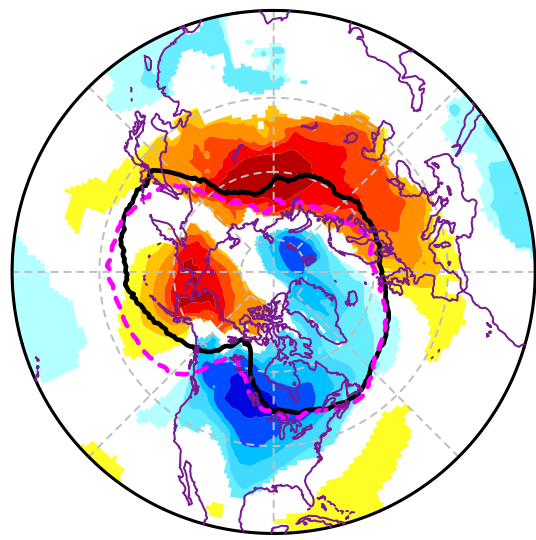

(c) KS+EA- minus KS-EA+ SOMs

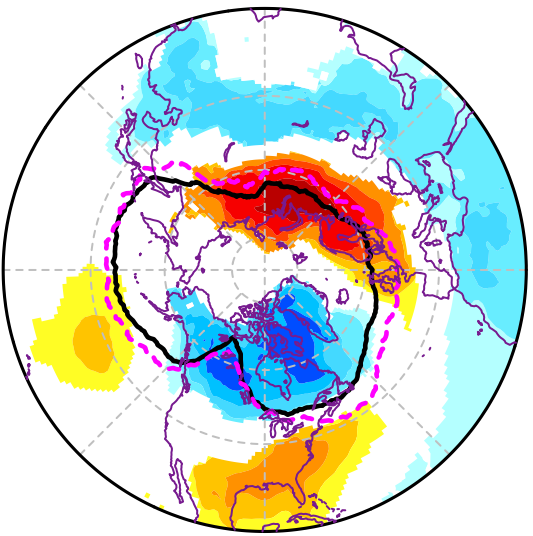

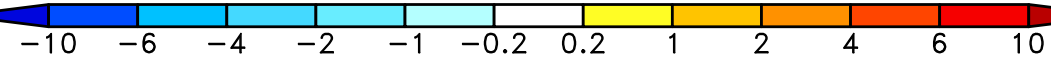

FIG. 8. Meridional positions of the maximum 850-hPa zonal wind at each longitude averaged over all matching days for the corresponding SAT SOMs during 1979-2018: (a) $\mathrm{NA}^{-} \mathrm{NE}^{-}$(black solid line) and $\mathrm{NA}^{+} \mathrm{NE}^{+}$(purple dashed line), (b) $\mathrm{NA}^{-} \mathrm{BS}^{+}$(black solid line) and NA ${ }^{+} \mathrm{BS}^{-}$ (purple dashed line), and (c) $\mathrm{KS}^{+} \mathrm{EA}^{-}$(black solid line) and $\mathrm{KS}^{-} \mathrm{EA}^{+}$(purple dashed line) SOMs. Differences of composite winter SAT anomalies (color shading; K) between positive and negative phases (defined in section 3a) are also plotted for the corresponding SAT pattern. Only anomalies statistically significant at the 95\% confidence level are plotted based on the Student's $t$ test.

and Zhang 2015; Yao et al. 2018). However, one should not consider that the LW anomalies are the cause of the SAT anomalies, as they all are part of the properties of the airmass advected into the region.

As shown in Fig. 9, the surface downward LW radiation anomalies are closely and positively correlated with SAT and $\theta_{850}$ anomalies associated with each of the SAT teleconnection patterns. This suggests that the SAT anomalies concur with similar temperature anomalies in the low-level atmosphere that are maintained by the corresponding downward LW radiation, which is determined mainly by low-level temperature and water vapor content (Zhang et al. 2011). Because water vapor content is largely determined by air temperature, which is closely coupled with SAT, there exists a close spatial agreement between the water vapor content and surface downward LW radiation anomalies (Fig. 9), and they are all related to the SAT patterns. Thus, for each of the SAT patterns, the SAT anomalies concur with the lower-tropospheric warm and moist (colder and dry) airmass from the midlatitudes (polar region), and the temperature and water vapor anomalies are accompanied by consistent anomalies in surface downward LW radiation. This further implies a dominant role of poleward movements of midlatitude warm and moist airmass and equatorward movements of polar cold and dry airmass in generating the winter SAT anomalies.

\section{b. Arctic sea ice condition}

Previous studies suggested that anomalous surface downward LW radiation associated with anomalous air temperature can play a role in causing sea ice concentration (SIC) anomalies (e.g., Wu et al. 2006; D.-S. R. Park et al. 2015; Gong and Luo 2017; Yao et al. 2018). To understand the concurrent relationship between the SAT patterns and the Arctic SIC, Fig. 10 shows the composites of Arctic SIC anomalies (color shading) together with the SAT anomalies (contours) for each of the SOM patterns. The SAT anomaly patterns are negatively correlated (spatial correlations ranging from -0.52 to -0.64 ) with the corresponding SIC anomaly patterns over the Arctic region (north of $50^{\circ} \mathrm{N}$ ). This suggests a connection between the two. The $\mathrm{NA}^{-} \mathrm{NE}^{-}$ $\left(\mathrm{NA}^{+} \mathrm{NE}^{+}\right.$) pattern is linked to reduced (enhanced) SIC over the Bering Sea and Baffin Bay and the opposite over the Hudson Bay (Figs. 10a,b). For the $\mathrm{NA}^{-} \mathrm{BS}^{+}$ $\left(\mathrm{NA}^{+} \mathrm{BS}^{-}\right.$) pattern (Figs. 10c,d), decreased (increased) SIC is mainly observed over the Bering Sea while the Okhotsk Sea sees the opposite. Note that the SIC over the Barents Sea is reduced considerably for the $\mathrm{NA}^{+} \mathrm{BS}^{-}$pattern (Fig. 10d) but changes slightly for the $\mathrm{NA}^{-} \mathrm{BS}^{+}$pattern (Fig. 10c). Furthermore, the KSEA pattern exhibits a direct connection with the SIC anomalies over the Barents-Kara Seas and Baffin Bay (Figs. 10e,f).

Atmospheric circulation plays a large role in determining SIC anomalies, including low-level winds and horizontal temperature advection (e.g., Thorndike and Colony 1982; Fang and Wallace 1994; Deser et al. 2000; Wu et al. 2006; Yuan et al. 2015). Comparison between anomalies of SIC (Fig. 10) and low-level circulation (Fig. 11) suggests that, for the $\mathrm{NA}^{-} \mathrm{NE}^{-}$and $\mathrm{NA}^{-} \mathrm{BS}^{+}$ 

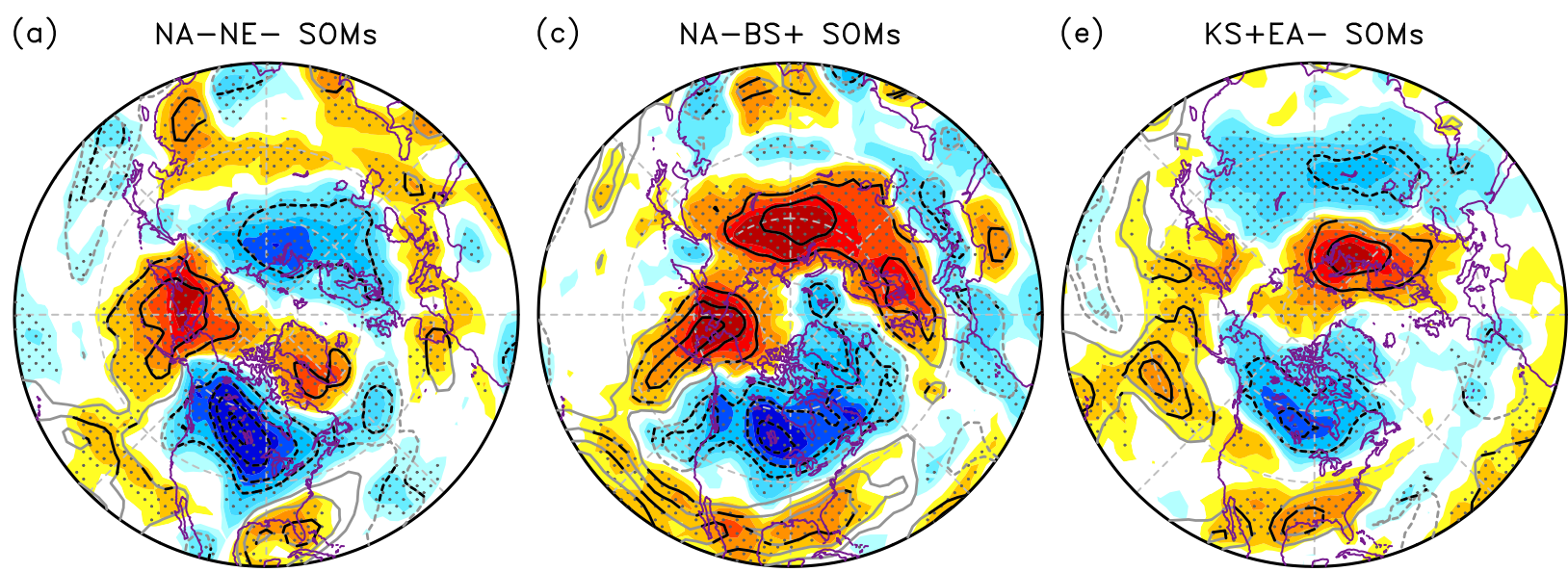

(b)

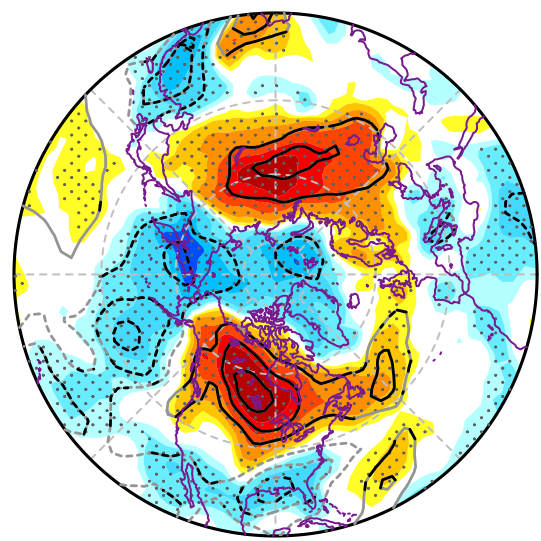

(d)

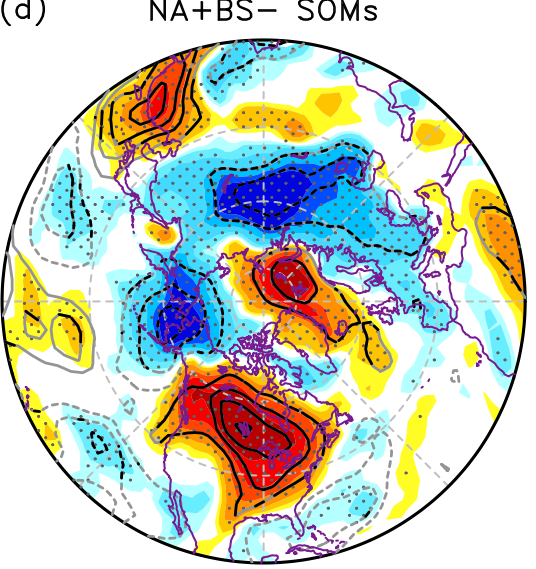

(f)

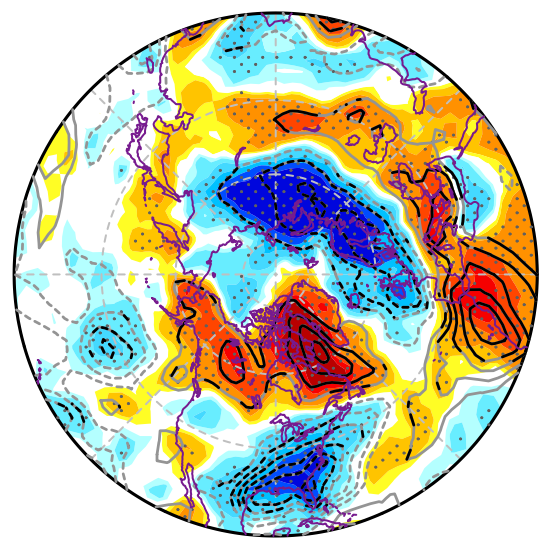

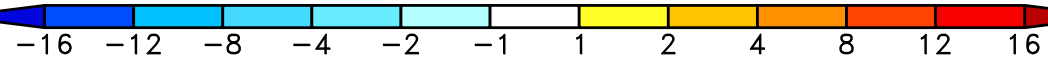

FIG. 9. Composites of winter surface downward longwave radiation anomalies (shading; $\mathrm{W} \mathrm{m}^{-2}$ ) and precipitable water anomalies (contours with an interval of $0.5 ; \mathrm{kg} \mathrm{m}^{-2}$; dashed contours are for negative values) in all matching days for the corresponding SAT SOMs during 1979-2018: (a),(b) NANE, (c),(d) NABS, and (e),(f) KSEA patterns. Stippling and black contours indicate that the anomalies are statistically significant at the $95 \%$ confidence level based on the Student's $t$ test.

patterns, anomalous southerly winds over the Bering Sea (Figs. 11a,c) can mechanically drive sea ice poleward, which can reduce SIC in this region (Figs. 10a,c), and the associated warm air masses from the low latitudes would also help melt the sea ice, both of which would lead to more heating of the atmospheric from the ocean. These processes are roughly the opposite for the $\mathrm{NA}^{+} \mathrm{NE}^{+}$and $\mathrm{NA}^{+} \mathrm{BS}^{-}$patterns. Similarly, larger SIC reduction over the Barents Sea for the $\mathrm{NA}^{+} \mathrm{BS}^{-}$ pattern (Fig. 10d) can be also partly explained by stronger southerly wind anomalies in the region (Fig. 11d). In particular, for some SAT patterns (e.g., the $\mathrm{NA}^{-} \mathrm{BS}^{+}, \mathrm{KS}^{+} \mathrm{EA}^{-}$, and $\mathrm{KS}^{-} \mathrm{EA}^{+}$patterns; Figs. $7 \mathrm{c}, \mathrm{e}, \mathrm{f})$, the associated anomalous SIC dipole pattern between the Labrador Sea and Greenland-Barents Sea is closely linked to the North Atlantic Oscillation (NAO)-like anomaly circulation over the North
Atlantic (Figs. 11c,e,f), as noticed previously (e.g., Walsh and Johnson 1979; Wang et al. 1994; Deser et al. 2000). On the other hand, warmer (colder) local SAT would also lead to lower (higher) SIC and larger (smaller) open water surfaces, and thus increased (decreased) winter oceanic heating of the lower troposphere through increased (decreased) upward LW radiation and turbulent heat fluxes (not shown), as the Arctic Ocean acts as a heat source to the atmosphere in the cold season (e.g., Serreze and Barry 2011; Dai et al. 2019; Deng et al. 2020). This extra oceanic heating would lead to more surface warming, forming a positive feedback to support and maintain these teleconnection patterns in SAT and SIC. Overall, the anomalous low-level winds and the associated movement of air masses play an essential role in altering SIC around the Arctic region. 
(a) NA-NE- SOMs, pr $=-0.55$

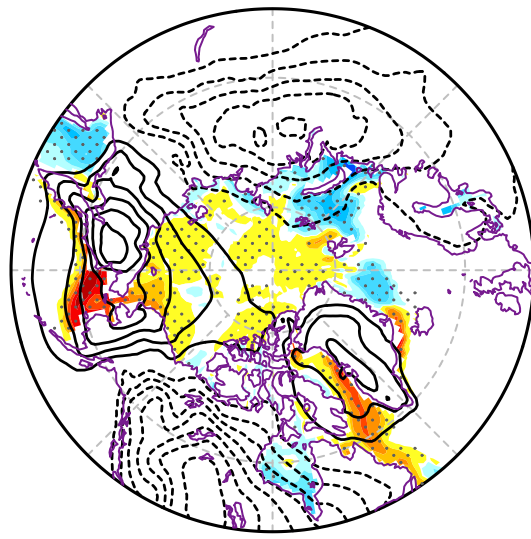

(b) $\mathrm{NA}+\mathrm{NE}+\mathrm{SOMs}, \mathrm{pr}=-0.52$

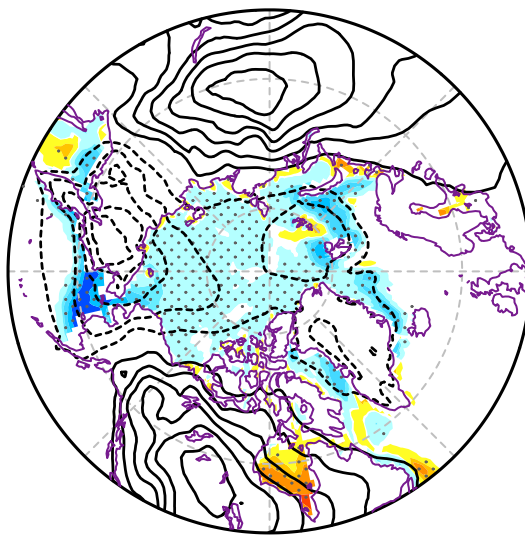

(c) NA-BS+ SOMs, pr $=-0.58$

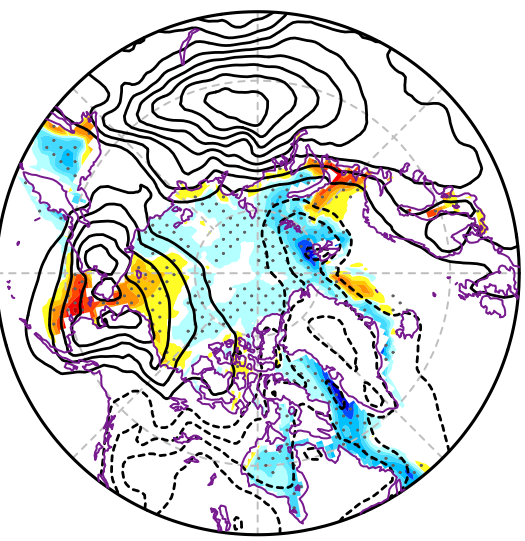

(d) NA+BS- SOMs, pr $=-0.58$

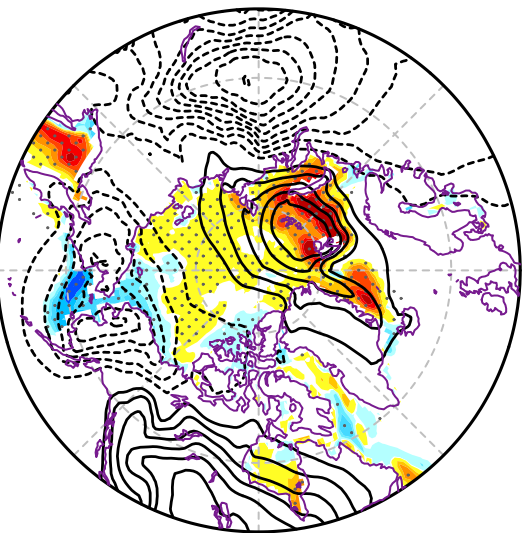

(e) $\mathrm{KS}+\mathrm{EA}-\mathrm{SOMs}, \mathrm{pr}=-0.61$

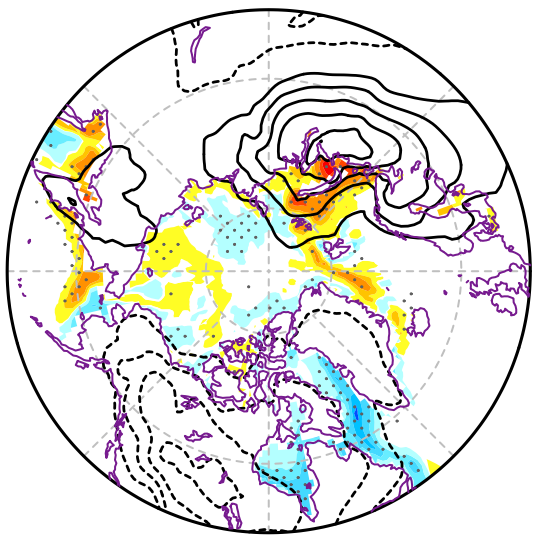

(f) $\mathrm{KS}-\mathrm{EA}+\mathrm{SOMs}, \mathrm{pr}=-0.64$

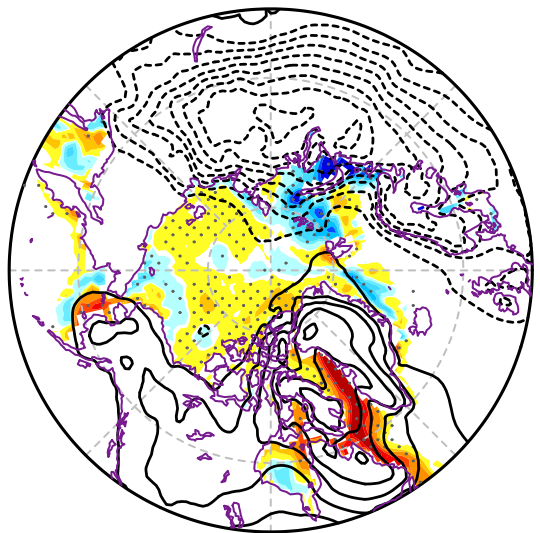

\section{\begin{tabular}{llllll|l|l|l|l|l|l|}
\hline & & & & & & & & & & & \\
-8 & -6 & -4 & -2 & -1 & -0.1 & 0.1 & 1 & 2 & 4 & 6 & 8
\end{tabular}}

FIG. 10. Composites of Arctic winter sea ice concentration (SIC) anomalies (shading; \% of area) and SAT anomalies (contours with an interval of 1; K; dashed contours are for negative values) in all matching days for the corresponding SAT SOMs during 1979-2018: (a),(b) NANE, (c),(d) NABS, and (e),(f) KSEA patterns. Stippling indicates that the anomalies are statistically significant at the $95 \%$ confidence level based on the Student's $t$ test. The pattern correlation (pr) between the SIC and SAT anomalies is given on the top of each panel.

\section{c. Sea surface temperature condition}

Winter SAT anomalies over the NH midlatitude continents can be linked to anomalous SSTs over both the tropical and midlatitude oceans, as noticed previously (e.g., Yu and Zhang 2015; Seager and Henderson 2016; Xie et al. 2017; Peng et al. 2018; Yu and Lin 2019). Figure 11 shows the composite SST anomalies associated with the SAT patterns. In association with the $\mathrm{NA}^{-} \mathrm{NE}^{-}$ $\left(\mathrm{NA}^{+} \mathrm{NE}^{+}\right.$) pattern, significant cold (warm) SST anomalies are seen over the equatorial central to eastern Pacific, central North Pacific, and central North Atlantic but warm (cold) SST anomalies are mainly seen in northern North Pacific (Figs. 11a,b). While the SST anomalies over the equatorial central-eastern Pacific Ocean are La Niña-like for the $\mathrm{NA}^{-} \mathrm{NE}^{-}$pattern (Fig. 11a) and El Niño-like for the $\mathrm{NA}^{+} \mathrm{NE}^{+}$pattern (Fig. 11b), their spatial extent is much narrower than those for typical La Niña or El Niño, whose tropical SST anomalies extend all the way to the eastern part of the North Pacific with opposite SST anomalies in the central North Pacific (Dong et al. 2018). Thus, the $\mathrm{NA}^{-} \mathrm{NE}^{-}$and $\mathrm{NA}^{+} \mathrm{NE}^{+} \mathrm{SAT}$ patterns are linked to ENSO-like SST anomalies over the tropical Pacific, although the associated SST anomalies over the North Pacific are not ENSO-like.

For the NABS patterns (Figs. 11c,d), some warm SST anomalies are seen in central North Pacific and central North Atlantic for the $\mathrm{NA}^{-} \mathrm{BS}^{+}$pattern (Fig. 11c), while some cold SST anomalies appear over the tropical central Pacific for the $\mathrm{NA}^{+} \mathrm{BS}^{-}$pattern (Fig. 11d). For the KSEA pattern (Figs. 11e,f), a tripole structure of anomalous SSTs are apparent over the Atlantic Ocean, with warm SST anomalies over the tropical Atlantic and northern North Atlantic and cold SST anomalies between 

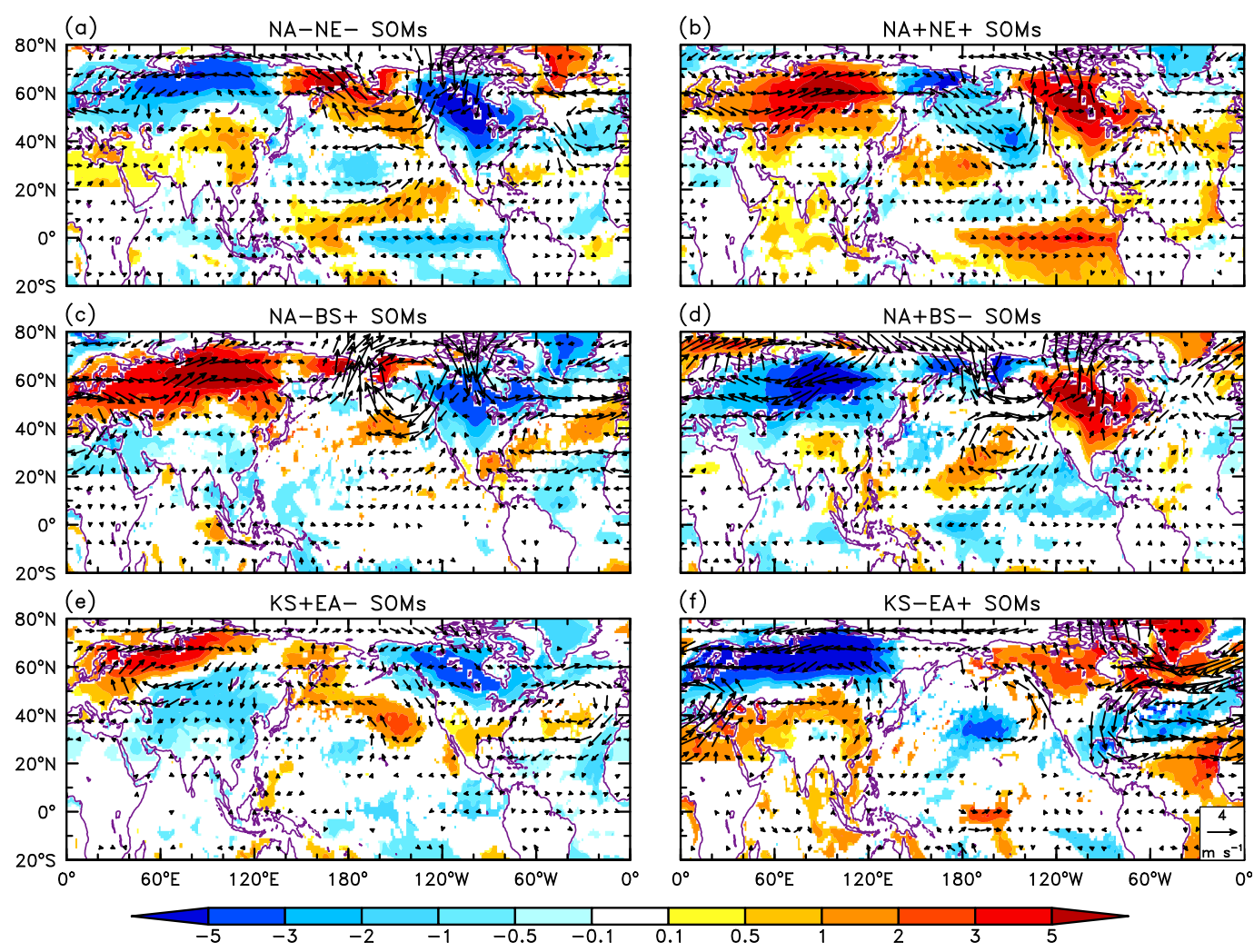

FIG. 11. Composite anomalies of winter sea surface temperatures (scaled by 10 in order to use the same color table; shading; K), SAT over land north of $20^{\circ} \mathrm{N}$ (shading; K) and $850-\mathrm{hPa}$ winds (vectors; $\mathrm{m} \mathrm{s}^{-1}$ ) in all matching days for the corresponding SAT SOMs during 1979-2018: (a),(b) NANE, (c),(d) NABS, and (e),(f) KSEA patterns. Only anomalies statistically significant at the $95 \%$ confidence level are plotted based on the Student's $t$ test.

them for the $\mathrm{KS}^{-} \mathrm{EA}^{+}$pattern (Fig. 11f). This pattern is roughly reversed but with weaker amplitudes for the $\mathrm{KS}^{+} \mathrm{EA}^{-}$pattern (Fig. 11e).

To further explore the concurrent relationships among the anomalous SAT, SST, and atmospheric circulation, composites of 850-hPa wind anomalies are also shown in Fig. 11. Please note that the relationship revealed here may only represent an association rather than a cause-or-effect relationship. For the $\mathrm{NA}^{-} \mathrm{NE}^{-}$ pattern (Fig. 11a), large southerly winds are seen over the Bering Sea while strong northerly winds occur over Canada and Europe. Further, there exists an anomalous cyclonic circulation associated with the underlying colder SSTs over the central North Pacific and North Atlantic, which transports the warm and moist air from the ocean to the polar region on the east side of the cyclone (Fig. 7a). For the $\mathrm{NA}^{+} \mathrm{NE}^{+}$pattern (Fig. 11b), it is roughly the opposite, with the warmer SST-related anomalous anticyclones over these two regions acting to transport the warm air from the ocean to the polar region on the west side of the anticyclones (Fig. 7b). Overall, these NANE-associated SST and circulation anomaly patterns are consistent with the findings of $\mathrm{Yu}$ and Lin (2019), who linked the North American winter SAT anomalies to the combination of the PNA pattern and the Asian-Bering-North American teleconnection.

The relationship between the SST and circulation anomaly patterns for the NABS pattern (Figs. 11c,d) are similar to the NANE pattern over the North PacificNorth America sector. For the $\mathrm{KS}^{+} \mathrm{EA}^{-}\left(\mathrm{KS}^{-} \mathrm{EA}^{+}\right)$ pattern (Figs. 7e,f), the eastward (westward) warm airflow originated over the northern North Atlantic is induced by the anticyclonic (cyclonic) anomaly circulation associated with the warm (cold) SST anomalies over the central North Atlantic (Figs. 11e,f). On the other hand, the SST anomaly patterns are likely also modulated by the anomalous circulation and the overlying SAT anomalies via air-sea interactions, as noticed previously (e.g., Cayan 1992; Kushnir et al. 2002; Yu and Zhang 2015). In particular, over the region around the Bering Strait, strong atmospheric anomaly advection may have produced the SAT anomalies, which would in turn affect the SSTs there. However, it is unclear whether the SST anomalies appear before the atmospheric circulation 
and SAT anomalies and thus may drive the circulation and SAT anomalies, or the SST anomalies follow the SAT anomalies and thus are an effect.

\section{Relationship between SAT SOMs and midlatitude cold/warm extremes}

Figure 12 shows the number of winter extreme cold and warm days, expressed in a percentage of the all matching days for each SAT SOM, averaged over North America, central Eurasia, and East Asia. The winter extreme cold (warm) days at each grid point are defined as daily SAT anomalies below (above) 1.5 standard deviations. On average, the winter extreme cold (warm) days occur in about $7.5 \%(5.5 \%)$ of all winter days during December 1979-February 2019. Clearly, SOMs 1, 5, 9, 13, and 17 (SOMs 4, 8, 12, 16, and 20) are more likely to produce cold (warm) extremes over North America, as indicated by their above-average percentages (Fig. 12a). Similarly, the cold (warm) extremes over central Eurasia are more likely to occur under SOMs 2-8, 11, and 12 (SOMs 1, 17, 18, and 20) (Fig. 12b), while SOMs 6, 8-15, and 19 (SOM 1-4) favor the occurrence of cold (warm) extremes over East Asia (Fig. 12c).

Figure 13 shows the time series of the accumulative number of extreme cold or warm days averaged over the three regions for each DJF from 1979 to 2018. Clearly, North America, central Eurasia, and East Asia have experienced more (less) extreme cold (warm) days in winters from 1998 to 2013, indicative of colder winters during this period over these regions, as noticed previously (e.g., Wallace et al. 2014; Wang and Chen 2014; Kug et al. 2015; Wu 2017). To better understand the interannual variability and interdecadal changes of regional winter extreme temperatures, we further link the number of extreme days over a target region mainly to the occurrence frequency of specific SOMs by the following two criteria: 1) the number of extreme days accounts for the above-average percentage of the matching days for this SOM, and 2) the positive correlation coefficient between these two time series is statistically significant at $90 \%$ confidence level (cf. Fig. 12). As a result, the number of winter cold (warm) extreme days is linked to the occurrence frequencies of SOMs 1 , 5, and 9 (SOM 20) for North America; SOMs 2-4, 6-8, and 11 (SOMs 17, 18, and 20) for central Eurasia; and SOMs 6, 8, 9, 12, and 13 (SOMs 3 and 4) for East Asia, respectively (Fig. 12). As shown in Fig. 13, the accumulative frequencies of these SOMs show significant positive correlations (ranging from 0.35 to 0.85 ) with their associated extreme days. Also, the frequency of the SOMs associated with winter cold (warm) extremes similarly exhibits increasing (decreasing) trends during

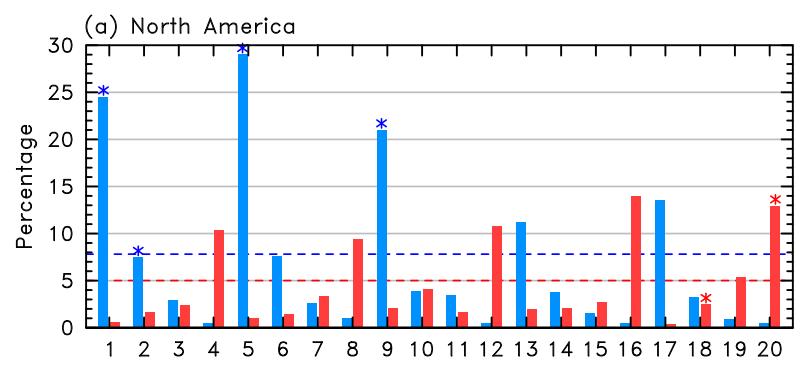

(b) Central Eurasia

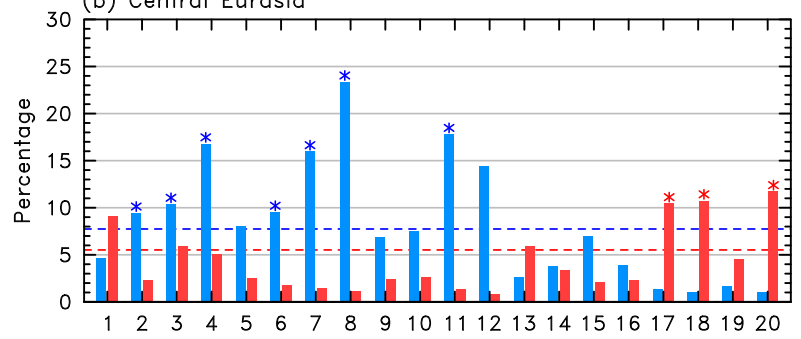

(c) East Asia

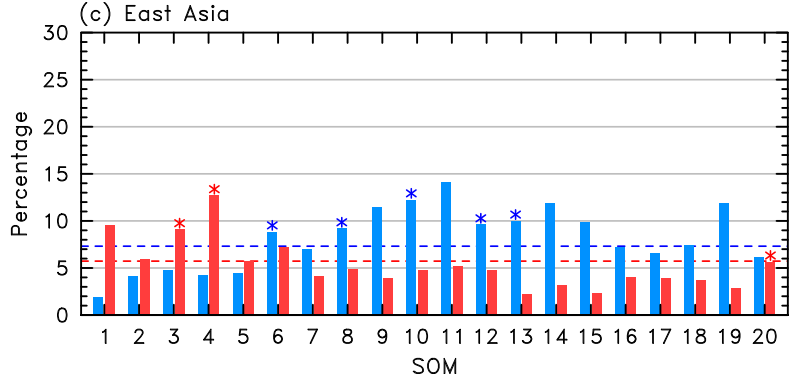

FIG. 12. The regionally averaged number of winter extreme cold (blue bars) and warm (red bars) days (expressed in percent of the matching days) over (a) NA, (b) CE, and (c) EA that occurred during all matching days for each SOM based on ERA-Interim daily data from 1979 to 2018 . The winter extreme cold (warm) days are defined as the linearly detrended daily SAT anomalies below (above) 1.5 standard deviations. The blue (red) dashed line represents the climatological percentage of the winter extreme cold (warm) days in all winter days from 1979 to 2018. The blue (red) asterisks indicate that the occurrence frequencies of the corresponding SAT SOMs are positively correlated with the numbers of winter extreme cold (warm) days at the $90 \%$ confidence level of significance.

1998-2013. This further suggests that the more (less) frequent cold (warm) extremes can be likely explained by the increasing (decreasing) occurrence of certain SOMs over the three regions.

\section{Summary and concluding remarks}

In this study, the main teleconnection patterns of winter surface air temperature (SAT) over the extratropical Northern Hemisphere (NH) are investigated, and their associated atmospheric and ocean conditions are also explored. Three distinct winter SAT teleconnection patterns are identified by applying the 

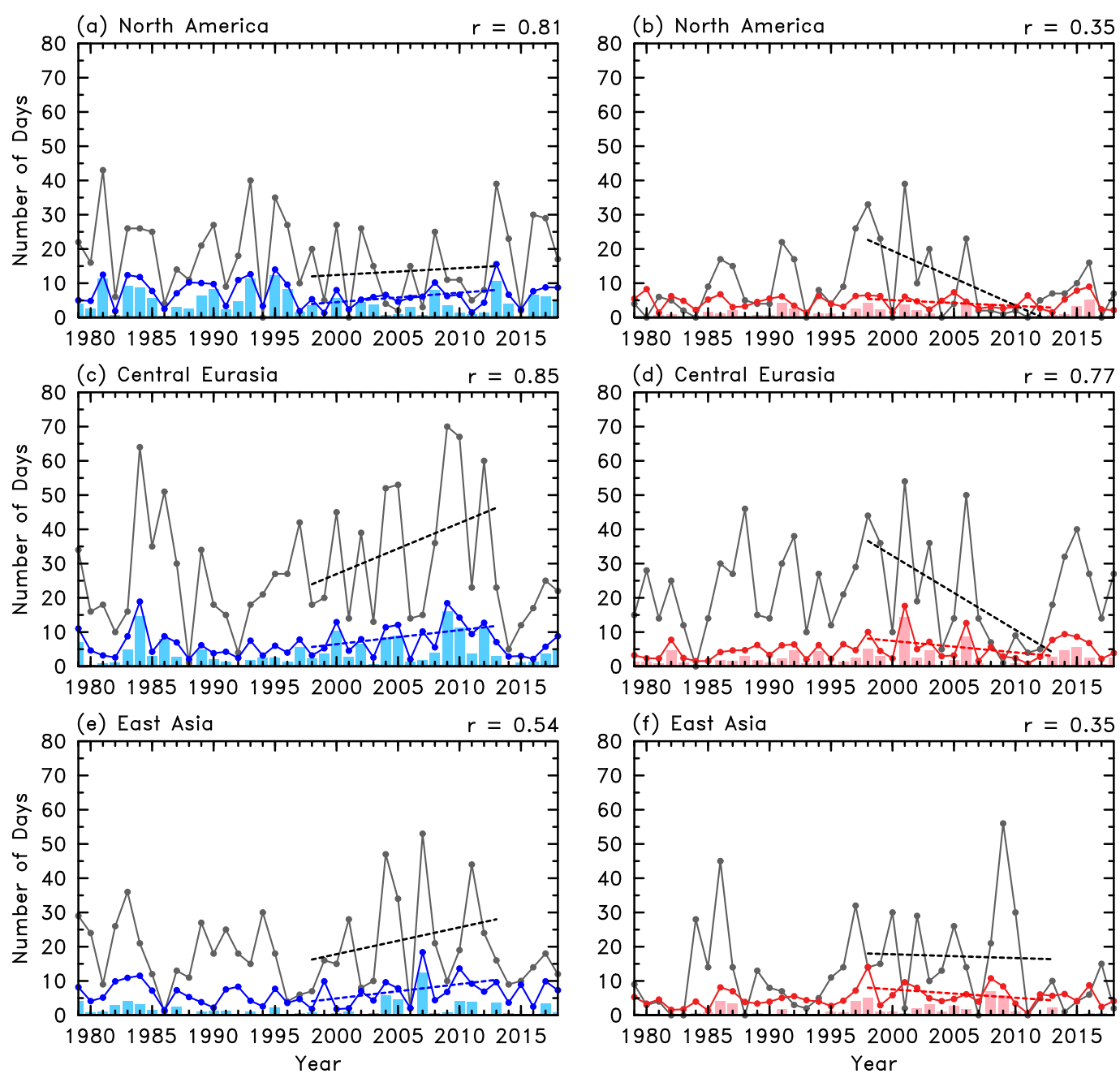

FIG. 13. Time series of the regionally averaged number of winter extreme (left) cold (blue line) and (right) warm (red line) days over (a),(b) NA, (c),(d) CE, and (e),(f) EA, and the occurrence frequencies (gray line) of the SOMs having the positive correlation with the extreme days (as marked with blue or red asterisks in Fig. 12). The bars are the number of extreme cold (blue bars) and warm (red bars) days associated with the corresponding SAT SOM days (gray line). The dashed line denotes the linear trend during 1998-2013 for the solid line with the same color.

self-organizing map (SOM) clustering approach to the deseasonalized and detrended daily SAT anomaly fields north of $20^{\circ} \mathrm{N}$ from ERA-Interim reanalysis for 40 winters (DJF) from December 1979 to February 2019. One distinct pattern exhibits concurrent SAT anomalies over North America and northern Eurasia with the same sign while the Arctic sees SAT anomalies with the opposite sign (NANE pattern). The other two patterns show SAT anomalies of opposite signs between North America and the Bering Sea (NABS pattern), and between the Kara Sea and East Asia (KSEA pattern), respectively. These SAT teleconnection patterns mainly represent a relationship of the signs of the winter SAT anomalies over different regions of the extratropical $\mathrm{NH}$, especially over North America, Eurasia, and the
Arctic region, rather than a correlation of the SAT anomalies. Thus, techniques based on correlations may not be able to detect these patterns. Each of the teleconnection patterns identified here has two phases of nearly opposite sign and a time scale of 7-12 days.

Further analyses revealed that these SAT anomaly patterns mainly result from meridional movements of cold and dry Arctic air (into the midlatitudes often over North America and Eurasia) and warm and moist midlatitude air (into the Arctic often through the Bering Sea and Greenland). These concurrent displacements of cold and warm airmasses out of and into the Arctic region are presumably part of the $\mathrm{NH}$ winter synoptic activities; they conserve the airmass over the Arctic region but cause pronounced and concurrent SAT 
anomalies over North America, Eurasia, and the Arctic region. Because the daily SAT of the original cold and warm airmasses before the displacement is usually uncorrelated, the SAT anomalies caused by these displaced airmasses are also typically uncorrelated (except for their sign of change relative to the local climatology).

Specifically, the $\mathrm{NA}^{-} \mathrm{NE}^{-}$pattern, which shows cold anomalies over North America and northern Eurasia and warm anomalies over the Bering Sea and Greenland, can be explained by the outbreak of the Arctic cold airmass into North America and Eurasia while a warm airmass from the North Pacific and North Atlantic Ocean intrudes into the Arctic region. The $\mathrm{NA}^{+} \mathrm{NE}^{+}$pattern shows opposite SAT anomalies and air movements. The $\mathrm{NA}^{-} \mathrm{BS}^{+}\left(\mathrm{NA}^{+} \mathrm{BS}^{-}\right)$pattern is closely related to the poleward movement of warm airmass from the North Pacific (North America), while the $\mathrm{KS}^{+} \mathrm{EA}^{-}\left(\mathrm{KS}^{-}\right.$ $\mathrm{EA}^{+}$) pattern is closely related to the poleward movement of warm airmass from Eurasia (the North Atlantic). These concurrent movements of cold and warm airmasses not only cause SAT anomalies but also induce changes in water vapor and LW radiation over the affected regions.

The occurrence frequency of the teleconnection patterns exhibits large interannual variations. In addition, the NABS and KSEA patterns also show significant trends since the late 1990s. The interannual variations and interdecadal changes of the winter monthly-mean SAT anomaly patterns may be interpreted as arising from changes in the occurrence frequency of the corresponding SOMs. Furthermore, the frequency of some SAT SOMs is also found to be closely related to the occurrences of winter extreme cold or warm events over the midlatitude continents. In particular, the observed increasing trend of winter cold extremes over North America, central Eurasia, and East Asia from 1998 to 2013 can be also explained by the increasing occurrences of certain SAT SOMs.

There are distinct anomalous atmospheric and ocean conditions associated with the SAT teleconnection patterns. The NANE pattern is closely related to anomalous SSTs over the tropical central-eastern Pacific (with ENSO-like patterns), midlatitude North Pacific, and North Atlantic, while the KSEA pattern is associated with SST anomalies over the North Pacific. The lower-tropospheric anomaly circulation associated with these anomalous SSTs acts to transport the warm air from the ocean to the midlatitude continent or the polar region. The NANE pattern is linked to similar SIC anomalies over the Bering Sea and Baffin Bay and the opposite SIC anomalies over Hudson Bay, while the NABS (KSEA) pattern is associated with anomalous SIC over the Bering Sea (the Barents-Kara Seas). Furthermore, both low-level southerly (northerly) wind anomalies and warm (cold) SAT anomalies can decrease (increase) SIC over the Arctic region, which would in turn enlarge the winter SAT anomalies through increased (reduced) upward LW radiation and heat fluxes, thus providing a positive feedback that enhances these SAT teleconnection patterns.

The SAT patterns revealed here by the SOM clustering help explain winter SAT variations over North America, Eurasia, and other parts of the extratropical $\mathrm{NH}$, in particular for explaining the concurrence of SAT anomalies of similar or opposite signs over different regions. However, what causes the meridional movements of the airmasses requires further investigations.

Acknowledgments. This work was jointly supported by the National Natural Science Foundation of China (Grant 41705054), Natural Science Foundation of Jiangsu Province (Grant BK20170942), General Program of Natural Science Research of Jiangsu Province University (Grant 17KJB170012), Startup Foundation for Introducing Talent of NUIST (Grant 2016r051), Priority Academic Program Development of Jiangsu Higher Education Institutions (PAPD), and China Scholarship Council (Grant 201808320137). A. Dai was supported by the National Science Foundation (AGS-1353740 and OISE1743738), the U.S. Department of Energy's Office of Science (DE-SC0012602), and the U.S. National Oceanic and Atmospheric Administration (NA15OAR4310086 and NA18OAR4310425).

\section{REFERENCES}

Abdillah, M. R., Y. Kanno, and T. Iwaski, 2017: Tropicalextratropical interactions associated with East Asian cold air outbreaks. Part I: Interannual variability. J. Climate, 30, 29893007, https://doi.org/10.1175/JCLI-D-16-0152.1.

Baxter, S., and S. Nigam, 2015: Key role of the North Pacific Oscillation-west Pacific pattern in generating the extreme 2013/14 North American winter. J. Climate, 28, 8109-8117, https://doi.org/10.1175/JCLI-D-14-00726.1.

Buishand, T. A., 1984: Tests for detecting a shift in the mean of hydrological time series. J. Hydrol., 73, 51-69, https://doi.org/ 10.1016/0022-1694(84)90032-5.

Cattiaux, J., R. Vautard, C. Cassou, P. Yiou, V. Masson-Delmotte, and F. Codron, 2010: Winter 2010 in Europe: A cold extreme in a warming climate. Geophys. Res. Lett., 37, L20704, https:// doi.org/10.1029/2010GL044613.

Cayan, D. R., 1992: Latent and sensible heat flux anomalies over the northern oceans: The connection to monthly atmospheric circulation. J. Climate, 5, 354-369, https://doi.org/10.1175/ 1520-0442(1992)005<0354:LASHFA $>2.0$.CO;2.

Chen, H. W., F. Zhang, and R. B. Alley, 2016: The robustness of midlatitude weather pattern changes due to Arctic sea ice loss. J. Climate, 29, 7831-7849, https://doi.org/10.1175/JCLI-D-160167.1.

Chen, R., W. Huang, B. Wang, Z. Yang, J. S. Wright, and W. Ma, 2017: On the cooccurrence of wintertime temperature 
anomalies over eastern Asia and eastern North America. $J$. Geophys. Res. Atmos., 122, 6844-6867, https://doi.org/10.1002/ 2016JD026435.

Chen, T.-C., W.-R. Huang, and J.-H. Yoon, 2004: Interannual variation of the East Asian cold surge activity. J. Climate, 17, 401-413, https://doi.org/10.1175/1520-0442(2004)017<0401: IVOTEA $>2.0 . \mathrm{CO} ; 2$.

Chen, X., and D. Luo, 2017: Arctic sea ice decline and continental cold anomalies: Upstream and downstream effects of Greenland blocking. Geophys. Res. Lett., 44, 3411-3419, https://doi.org/ 10.1002/2016GL072387.

Chen, Z., R. Wu, and W. Chen, 2014: Distinguishing interannual variations of the northern and southern modes of the East Asian winter monsoon. J. Climate, 27, 835-851, https://doi.org/ 10.1175/JCLI-D-13-00314.1.

Cohen, J., J. Foster, M. Barlow, K. Saito, and J. Jones, 2010: Winter 20092010: A case study of an extreme Arctic Oscillation event. Geophys. Res. Lett., 37, L17707, https://doi.org/10.1029/2010GL044256.

— treme mid-latitude weather. Nat. Geosci., 7, 627-637, https:// doi.org/10.1038/ngeo2234.

Czaja, A., and J. Marshall, 2006: The partitioning of poleward heat transport between the atmosphere and ocean. J. Atmos. Sci., 63, 1498-1511, https://doi.org/10.1175/JAS3695.1.

Dai, A., and M. Song, 2020: Little influence of Arctic amplification on midlatitude climate. Nat. Climate Change, 10, 231-237, https://doi.org/10.1038/s41558-020-0694-3.

—, D. Luo, M. Song, and J. Liu, 2019: Arctic amplification is caused by sea-ice loss under increasing $\mathrm{CO}_{2}$. Nat. Commun., 10, 121, https://doi.org/10.1038/s41467-018-07954-9.

Dee, D. P., and Coauthors, 2011: The ERA-Interim reanalysis: Configuration and performance of the data assimilation system. Quart. J. Roy. Meteor. Soc., 137, 553-597, https://doi.org/ 10.1002/qj.828.

Deng, J., A. Dai, and H. Xu, 2020: Nonlinear climate responses to increasing $\mathrm{CO}_{2}$ and anthropogenic aerosols simulated by CESM1. J. Climate, 33, 281-301, https://doi.org/10.1175/JCLID-19-0195.1.

Deser, C., J. E. Walsh, and M. S. Timlin, 2000: Arctic sea ice variability in the context of recent atmospheric circulation trends. J. Climate, 13, 617-633, https://doi.org/10.1175/1520-0442(2000) 013<0617:ASIVIT $>2.0 . \mathrm{CO} ; 2$.

Dong, B., A. Dai, M. Vuille, and O. Elison Timm, 2018: Asymmetric modulation of ENSO teleconnections by the interdecadal Pacific oscillation. J. Climate, 31, 7337-7361, https:// doi.org/10.1175/JCLI-D-17-0663.1.

Fang, Z., and J. M. Wallace, 1994: Arctic sea ice variability on a timescale of weeks and its relation to atmospheric forcing. J. Climate, 7, 1897-1914, https://doi.org/10.1175/1520-0442(1994) 007<1897:ASIVOA > 2.0.CO;2.

Francis, J. A., and S. J. Vavrus, 2012: Evidence linking Arctic amplification to extreme weather in mid-latitudes. Geophys. Res. Lett., 39, L06801, https://doi.org/10.1029/2012GL051000.

Gervais, M., E. Atallah, J. R. Gyakum, and L. B. Tremblay, 2016: Arctic air masses in a warming world. J. Climate, 29, 2359 2373, https://doi.org/10.1175/JCLI-D-15-0499.1.

Gong, T., and D. Luo, 2017: Ural blocking as an amplifier of the Arctic sea ice decline in winter. J. Climate, 30, 2639-2654, https://doi.org/10.1175/JCLI-D-16-0548.1.

Iwasaki, T., T. Shoji, Y. Kanno, M. Sawada, M. Ujiie, and K. Takaya, 2014: Isentropic analysis of polar cold airmass streams in the Northern Hemispheric winter. J. Atmos. Sci., 71, 2230-2243, https://doi.org/10.1175/JAS-D-13-058.1.
Johnson, N. C., and S. B. Feldstein, 2010: The continuum of North Pacific sea level pressure patterns: Intraseasonal, interannual, and interdecadal variability. J. Climate, 23, 851-867, https:// doi.org/10.1175/2009JCLI3099.1.

Jung, T., T. N. Palmer, M. J. Rodwell, and S. Serrar, 2010: Understanding the anomalously cold European winter of 2005/06 using relaxation experiments. Mon. Wea. Rev., 138 3157-3174, https://doi.org/10.1175/2010MWR3258.1.

Kanamitsu, M., W. Ebisuzaki, J. Woollen, S.-K. Yang, J. J. Hnilo, M. Fiorino, and G. L. Potter, 2002: NCEP-DOE AMIP-II Reanalysis (R-2). Bull. Amer. Meteor. Soc., 83, 1631-1644, https://doi.org/10.1175/BAMS-83-11-1631.

Kanno, Y., M. R. Abdillah, and T. Iwasaki, 2015: Charge and discharge of polar cold air mass in Northern Hemispheric winter. Geophys. Res. Lett., 42, 7187-7193, https://doi.org/10.1002/ 2015GL065626.

Kohonen, T., 2001: Self-Organizing Maps. 3rd ed. Springer, 521 pp. Kug, J.-S., J.-H. Jeong, Y.-S. Jang, B.-M. Kim, C. K. Folland, S.-K. Min, and S.-W. Son, 2015: Two distinct influences of Arctic warming on cold winters over North America and East Asia. Nat. Geosci., 8, 759-762, https://doi.org/10.1038/ngeo2517.

Kushnir, Y., W. A. Robinson I. Bladé, N. M. J. Hall, S. Peng, and R. Sutton, 2002: Atmospheric GCM response to extratropical SST anomalies: Synthesis and evaluation. J. Climate, 15, 22332256, https://doi.org/10.1175/1520-0442(2002)015<2233:AGRTES> 2.0.CO;2.

Lee, M.-H., S. Lee, H.-J. Lee, and C.-H. Ho, 2017: The recent increase in the occurrence of a boreal summer teleconnection and its relationship with temperature extremes. J. Climate, $\mathbf{3 0}$, 7493-7504, https://doi.org/10.1175/JCLI-D-16-0094.1.

Lin, H., 2015: Subseasonal variability of North American wintertime surface air temperature. Climate Dyn., 45, 1137-1155, https://doi.org/10.1007/s00382-014-2363-6.

- 2018: Predicting the dominant patterns of subseasonal variability of wintertime surface air temperature in extratropical Northern Hemisphere. Geophys. Res. Lett., 45, 4381-4389, https://doi.org/10.1029/2018GL077509.

Linkin, M., and S. Nigam, 2008: The North Pacific Oscillation-west Pacific teleconnection pattern: Mature-phase structure and winter impacts. J. Climate, 21, 1979-1997, https://doi.org/ 10.1175/2007JCLI2048.1.

Loikith, P. C., L. A. Pampuch, E. Slinskey, J. Detzer, C. R. Mechoso, and A. Barkhordarian, 2019: A climatology of daily synoptic circulation patterns and associated surface meteorology over southern South America. Climate Dyn., 53, 40194035, https://doi.org/10.1007/s00382-019-04768-3.

Lu, M.-M., and C.-P. Chang, 2009: Unusual late-season cold surges during the 2005 Asian winter monsoon: Roles of Atlantic blocking and the central Asian anticyclone. J. Climate, 22, 5205-5217, https://doi.org/10.1175/2009JCLI2935.1.

Luo, D., Y. Xiao, Y. Yao, A. Dai, I. Simmonds, and C. L. E. Franzke, 2016: Impact of Ural blocking on winter warm Arctic-cold Eurasian anomalies. Part I: Blocking-induced amplification. J. Climate, 29, 3925-3947, https://doi.org/10.1175/ JCLI-D-15-0611.1.

$\longrightarrow$, X. Chen, A. Dai, and I. Simmonds, 2018: Changes in atmospheric blocking circulations linked with winter Arctic warming: A new perspective. J. Climate, 31, 7661-7678, https://doi.org/ 10.1175/JCLI-D-18-0040.1.

, — , J. Overland, I. Simmonds, Y. Wu, and P. Zhang, 2019: Weakened potential vorticity barrier linked to recent winter Arctic sea ice loss and midlatitude cold extremes. J. Climate, 32, 4235-4261, https://doi.org/10.1175/JCLI-D-18-0449.1. 
Ma, S., and C. Zhu, 2019: Extreme cold wave over East Asia in January 2016: A possible response to the larger internal atmospheric variability induced by Arctic warming. $J$. Climate, 32, 1203-1216, https://doi.org/10.1175/JCLI-D-180234.1.

McCusker, K. E., J. C. Fyfe, and M. Sigmond, 2016: Twenty-five winters of unexpected Eurasian cooling unlikely due to Arctic sea-ice loss. Nat. Geosci., 9, 838-842, https://doi.org/10.1038/ ngeo2820.

Masselink, G., B. Castelle, T. Scott, G. Dodet, S. Suanez, D. Jackson, and F. Floc'h, 2016: Extreme wave activity during 2013/2014 winter and morphological impacts along the Atlantic coast of Europe. Geophys. Res. Lett., 43, 2135-2143, https://doi.org/ 10.1002/2015GL067492.

Overland, J. E., K. R. Wood, and M. Y. Wang, 2011: Warm Arcticcold continents: Climate impacts of the newly open Arctic Sea. Polar Res., 30, 15787, https://doi.org/10.3402/polar.v30i0. 15787.

_ J. Jrancis, R. Hall, E. Hanna, S. Kim, and T. Vihma, 2015: The melting Arctic and mid-latitude weather patterns: Are they connected? J. Climate, 28, 7917-7932, https://doi.org/ 10.1175/JCLI-D-14-00822.1.

Park, D.-S. R., S. Lee, and S. B. Feldstein, 2015: Attribution of the recent winter sea ice decline over the Atlantic sector of the Arctic Ocean. J. Climate, 28, 4027-4033, https://doi.org/10.1175/ JCLI-D-15-0042.1.

Park, T.-W., C.-H. Ho, and Y. Song, 2011: Relationship between the Arctic Oscillation and cold surges over East Asia J. Climate, 24, 68-83, https://doi.org/10.1175/2010JCLI3529.1.

- - — J.-H. Jeong, J.-W. Heo, and Y. Deng, 2015: A new dynamical index for classification of cold surge types over East Asia. Climate Dyn., 45, 2469-2484, https://doi.org/10.1007/ s00382-015-2483-7.

Peng, P., A. Kumar, M. Chen, Z.-Z. Hu, and B. Jha, 2018: Was the North American extreme climate in winter 2013/14 a SST forced response? Climate Dyn., 52, 3099-3110, https://doi.org/ 10.1007/s00382-018-4314-0.

Qian, C., and Coauthors, 2018: Human influence on the recordbreaking cold event in January of 2016 in eastern China. Bull. Amer. Meteor. Soc., 99, S118-S122, https://doi.org/10.1175/ BAMS-D-17-0095.1.

Seager, R., and N. Henderson, 2016: On the role of tropical ocean forcing of the persistent North American west coast ridge of winter 2013/14. J. Climate, 29, 8027-8049, https://doi.org/ 10.1175/JCLI-D-16-0145.1.

Serreze, M. C., and R. G. Barry, 2011: Processes and impacts of Arctic amplification: A research synthesis. Global Planet. Change, 77, 85-96, https://doi.org/10.1016/j.gloplacha.2011.03.004.

Singh, D., D. Swain, J. Mankin, D. Horton, L. Thomas, B. Rajaratnam, and N. Diffenbaugh, 2016: Recent amplification of the North American winter temperature dipole. J. Geophys. Res. Atmos., 121, 9911-9928, https://doi.org/10.1002/2016JD025116.

Song, L., and R. Wu, 2018: Comparison of intraseasonal East Asian winter cold temperature anomalies in positive and negative phases of the Arctic Oscillation. J. Geophys. Res. Atmos., 123, 8518-8537, https://doi.org/10.1029/2018JD028343.

Sun, L., J. Perlwitz, and M. Hoerling, 2016: What caused the recent "warm Arctic, cold continents" trend pattern in winter temperatures? Geophys. Res. Lett., 43, 5345-5352, https://doi.org/ 10.1002/2016GL069024.

Thompson, D. W. J., M. P. Baldwin, and J. M. Wallace, 2002: Stratospheric connection to Northern Hemisphere wintertime weather: Implications for prediction. J. Climate, 15, 1421-
1428, https://doi.org/10.1175/1520-0442(2002)015<1421: SCTNHW $>2.0 . \mathrm{CO} ; 2$.

Thorndike, A. S., and R. Colony, 1982: Sea ice motion in response to geostrophic winds. J. Geophys. Res., 87, 5845-5852, https:// doi.org/10.1029/JC087iC08p05845.

Wallace, J. M., I. M. Held, D. W. Thompson, K. E. Trenberth, and J. E. Walsh, 2014: Global warming and winter weather. Science, 343, 729-730, https://doi.org/10.1126/science.343. 6172.729.

Walsh, J. E., and C. M. Johnson, 1979: Interannual atmospheric variability and associated fluctuations in Arctic sea ice extent. J. Geophys. Res., 84, 6915-6928, https://doi.org/10.1029/ JC084iC11p06915.

Wang, H., and R. Fu, 2000: Winter monthly mean atmospheric anomalies over the North Pacific and North America associated with El Niño SSTs. J. Climate, 13, 3435-3447, https:// doi.org/10.1175/1520-0442(2000)013<3435: WMMAAO $>2.0 . \mathrm{CO} ; 2$.

Wang, J., L. A. Mysak, and R. G. Ingram, 1994: Interannual variability of sea-ice cover in Hudson Bay, Baffin Bay and the Labrador Sea. Atmos.-Ocean, 32, 421-447, https://doi.org/ 10.1080/07055900.1994.9649505.

Wang, L., and W. Chen, 2014: The East Asian winter monsoon: Reamplification in the mid-2000s. Chin. Sci. Bull., 59, 430-436, https://doi.org/10.1007/s11434-013-0029-0.

Wang, S. S., W.-R. Huang, and J.-H. Yoon, 2015: The North American winter 'dipole' and extremes activity: A CMIP5 assessment. Atmos. Sci. Lett., 16, 338-345, https://doi.org/ 10.1002/asl2.565.

Westby, R. M., Y. Y. Lee, and R. X. Black, 2013: Anomalous temperature regimes during the cool season: Long-term trends, low-frequency mode modulation, and representation in CMIP5 simulations. J. Climate, 26, 9061-9076, https:// doi.org/10.1175/JCLI-D-13-00003.1.

Wu, B., 2017: Winter atmospheric circulation anomaly associated with recent Arctic winter warm anomalies. J. Climate, 30, 8469-8479, https://doi.org/10.1175/JCLI-D-17-0175.1.

, J. Wang, and J. E. Walsh, 2006: Dipole anomaly in the winter Arctic atmosphere and its association with sea ice motion. J. Climate, 19, 210-225, https://doi.org/10.1175/JCLI3619.1.

—, D. Handorf, K. Dethloff, A. Rinke, and A. Hu, 2013: Winter weather patterns over northern Eurasia and Arctic sea ice loss. Mon. Wea. Rev., 141, 3786-3800, https://doi.org/10.1175/MWRD-13-00046.1.

_ K. Kang, and J. A. Francis, 2017: A cold event in Asia during January-February 2012 and its possible association with Arctic sea ice loss. J. Climate, 30, 7971-7990, https://doi.org/ 10.1175/JCLI-D-16-0115.1.

Xie, J., and M. Zhang, 2017: Role of internal atmospheric variability in the 2015 extreme winter climate over the North American continent. Geophys. Res. Lett., 44, 2464-2471, https://doi.org/10.1002/2017GL072772.

Xie, Z., R. X. Black, and Y. Deng, 2017: The structure and largescale organization of extreme cold waves over the conterminous United States. Climate Dyn., 49, 4075-4088, https:// doi.org/10.1007/s00382-017-3564-6.

Yao, Y., D. Luo, A. Dai, and I. Simmonds, 2017: Increased quasi stationarity and persistence of winter Ural blocking and Eurasian extreme cold events in response to Arctic warming. Part I: Insights from observational analyses. J. Climate, 30, 3549-3568, https://doi.org/10.1175/JCLI-D-16-0261.1.

, — - and L. Zhong, 2018: Effects of Northern Hemisphere atmospheric blocking on Arctic sea ice decline in winter at 
weekly time scales. Atmosphere, 9, 331, https://oi.org/10.3390/ atmos 9090331.

Yu, B., and X. Zhang, 2015: A physical analysis of the severe 2013/2014 cold winter in North America. J. Geophys. Res. Atmos., 120, 10 149-10 165, https://doi.org/10.1002/2015 JD023116.

, and H. Lin, 2019: Modification of the wintertime PacificNorth American pattern related North American climate anomalies by the Asian-Bering-North American telecon- nection. Climate Dyn., 53, 313-328, https://doi.org/10.1007/ s00382-018-4586-4.

Yuan, J., B. Tan, S. B. Feldstein, and S. Lee, 2015: Wintertime North Pacific teleconnection patterns: Seasonal and interannual variability. J. Climate, 28, 8247-8263, https://doi.org/ 10.1175/JCLI-D-14-00749.1.

Zhang, T., M. P. Hoerling, J. Perlwitz, D.-Z. Sun, and D. Murray, 2011: Physics of U.S. surface temperature response to ENSO. J. Climate, 24, 4874-4887, https://doi.org/10.1175/2011JCLI3944.1. 